\title{
A região cárstica dos Campos Gerais, Paraná-São Paulo, Brasil: revisão de conceitos, potencial espeleológico e políticas públicas de geoconservação
}

\author{
Henrique Simão PONTES ${ }^{1}$, Luiz Alberto FERNANDES², Mário Sérgio de MELO ${ }^{3}$ \& Laís \\ Luana MASSUQUETO4 \\ 1 Grupo Universitário de Pesquisas Espeleológicas (GUPE) e Departamento de Geociências da Universidade \\ Estadual de Ponta Grossa. Av. General Carlos Cavalcanti, 4748, Uvaranas, CEP 84030-900, Ponta Grossa, \\ PR, Brasil (henriquegeografo@gmail.com). \\ 2 Programa de Pós-graduação em Geologia da Universidade Federal do Paraná. Av. Cel. Francisco H. dos \\ Santos, 100, Jardim das Américas, CEP 81530-000, Curitiba, PR, Brasil (lufernandes@ufpr.br) \\ 3 Departamento de Geociências, Universidade Estadual de Ponta Grossa (msmelo1952@gmail.com). \\ ${ }^{4}$ Grupo Universitário de Pesquisas Espeleológicas (GUPE) (lais.massuqueto@gmail.com).
}

Resumo. A região cárstica dos Campos Gerais (RCCG), situada nos estados do Paraná e São Paulo, é considerada uma nova região cárstica brasileira. A área congrega várias cavernas e feições típicas de relevo cárstico, desenvolvido em rochas da Formação Furnas e da subunidade Vila Velha pertencente à Formação Campo Mourão (Grupo Itararé), compostas, sobretudo por quartzoarenitos. Os conceitos de região cárstica, província espeleológica e distrito espeleológico se confundem e até mesmo são utilizados como sinônimos. Propõe-se aqui nova conceituação para estes termos visando seu uso na gestão de territórios, políticas públicas e geoconservação. Apresenta-se um algoritmo matemático para estabelecimento do potencial espeleológico estimado (PEE) de uma área, para indicar parâmetros menos subjetivos sobre a possibilidade de existência de cavernas. 0 cálculo proposto tem como foco evitar parâmetros vagos, como a ausência ou baixo potencial de ocorrência de cavidades e rochas carbonáticas. Após tal revisão de conceitos, apresentação do PEE e registro da nova região cárstica, são apontados problemas nas políticas públicas e procedimentos administrativos na esfera estadual e municipal, com foco de análise no distrito cárstico de Ponta Grossa (DCPG), área de maior concentração de cavernas da RCCG. Presença de problemas legais e em procedimentos administrativos apontam os riscos na proteção do patrimônio geológico da área frente às atividades e empreendimentos de significativo potencial degradador. Ao final, conclui-se que a gestão do território na RCCG necessita de controle diferenciado sobre o uso e ocupação do solo devido às suas fragilidades ambientais, orientado por instrumentos de gestão claros e concisos, adotando-se sempre o princípio da precaução.

Palavras-chave. carste não carbonático, quartzoarenitos, gestão do território, legislação, licenciamento ambiental espeleológico.

Abstract. Campos Gerais karst region, PARANÁ/SÃo PaUlo, Brasil: Concepts ReVIeW, SPELEOLOGICAL POTENTIAL AND GEOCONSERVATION PUBLIC POLICIES. The karst region of Campos Gerais (KRCG), located in the states of Paraná and São Paulo, is considered a new karst area in Brazil. The area congregates several caves and typical features of karst relief, developed in rocks of the Furnas Formation and Vila Velha subunit of Campo Mourão Formation (Itararé Group), composed mainly of quartz sandstones. The concepts of karst region, speleological province and speleological district are often confused and used interchangeably. A new concept for these terms is proposed here, aiming at their use in the territory management, public policies and geoconservation. It presents a mathematical algorithm to establish the estimated speleological potential (ESP) of an area, aims to indicate parameters less subjective about the possibility of caves occurrence. The proposed calculation aims to avoid vague parameters, such as the absence or low potential for the occurrence of cavities and carbonate rocks. After concepts review, presentation of the EEP and registration of the new karst region, problems in the public policies and administrative procedures at the state and municipal level are discussed, with a focus on analysis in the Ponta Grossa karst district (PGKD), the area of greatest concentration of caves in RCCG. Legal problems and administrative procedures point out the risks in the protection of the area's geological heritage in the face of activities and undertakings with significant degrading potential. At the end, it is concluded that the territory management in the RCCG needs differentiated 
control over the land use and occupation due to its environmental weaknesses, guided by clear and concise management instruments, always adopting the precautionary principle.

Keywords. non-carbonate karst, quartz sandstones, territory management, legislation, speleological environmental licensing.

\section{Introdução}

A conservação de cavernas e dos relevos cársticos no Brasil é regulada por um conjunto de decretos, leis e normativas que definem as formas de uso e gestão deste patrimônio (e.g. BRASIL, 1988, 1990, 2008). Contudo, a falta de adequada classificação das regiões cársticas não carbonáticas (no caso analisado, em quartzoarenitos), enquadramentos de potencialidade espeleológica em níveis baixos, desproporcional a real dimensão da ocorrência de cavernas de determinados territórios, e um conjunto de dispositivos legais com lacunas e problemas, proporciona riscos à proteção dos relevos cársticos e das feições superficiais e subterrâneas associadas.

As primeiras propostas metodológicas voltadas à identificação e espacialização das áreas cársticas brasileiras referem-se a rochas carbonáticas (calcários, dolomitos e seus correspondentes metamórficos). Pioneiros nesta discussão, Karmann \& Sanchez (1979) propuseram uma classificação a partir de províncias espeleológicas e distritos espeleológicos.

Segundo os autores, província espeleológica é uma região pertencente à mesma unidade geológica, composta por rochas carbonáticas, onde ocorrem feições cársticas e agrupamentos de cavernas. Para Karmann \& Sanchez (1979), as províncias podem ser divididas em distritos, classificados como áreas de maior concentração espeleológica. Assim, a definição de província espeleológica está intrinsecamente relacionada à mesma unidade geológica e conjuntos de cavernas.

Karmann \& Sanchez (1979) também apresentam o conceito de região carbonática proposto para designar áreas desenvolvidas em rochas carbonáticas, mas que apresentam baixa ocorrência de cavernas e/ou condições geológicas desfavoráveis para a formação de cavidades subterrâneas. Após cerca de uma década, Karmann \& Sanchez (1988) indicaram oito principais provinciais espeleológicas para o desenvolvimento de cavernas no território nacional. Neste total, os autores incluíram duas províncias formadas em rochas não carbonáticas, denominadas Serra Geral e Rio Urubu Superior.

Para o estado do Paraná, Martins (1985) e Karmann \& Sanchez (1988) propuseram a Província Serra Geral, correspondendo com uma estreita faixa de arenitos do Grupo São Bento, incluindo os estados de São Paulo, Santa Catarina e Rio Grande do Sul. Parellada (1989) definiu seis províncias espeleológicas no Paraná, três carbonáticas (grupos Açungui e Setuva e Formação Rio Bonito) e três não carbonáticas (Formação Furnas, grupos Itararé e São Bento). Contudo, conforme o mapeamento geológico atual do estado do Paraná são cinco áreas carbonáticas (Formação Bairro dos Campos, Formação Águas Claras, Formação Capiru, Formação Votuverava e Formação Irati), salientando que a Formação Rio Bonito não é caracterizada como uma unidade carbonática.

Auler et al. (2001) e Auler (2002) utilizaram o mapa geológico na escala de 1:2.500.000 para definir quatorze áreas cársticas no Brasil, todas desenvolvidas em rochas carbonáticas. Estes autores foram os primeiros a utilizar o conceito de região cárstica, por entenderem que cavernas são uma das variadas feições componentes de um relevo cárstico.

Spoladore (2005) adotou a classificação de Karmann \& Sanchez (1979), utilizou os conceitos província e distrito espeleológico, seguiu a proposta de Parellada (1989) referente às três províncias espeleológicas não carbonáticas (areníticas) no Paraná e as subdividiu em nove distritos espeleológicos.

No ano de 2009, o Centro Nacional de Pesquisas e Conservação de Cavernas (CECAV), 
órgão ligado ao Instituto Chico Mendes de Conservação da Biodiversidade (ICMBio), apresentou nova classificação de escala nacional, baseando-se no conceito de região cárstica (CECAV, 2009). Este trabalho resultou no reconhecimento de dezenove regiões cársticas no Brasil.

Atualmente, a legislação espeleológica, as diretrizes para a conservação do patrimônio espeleológico brasileiro e a gestão das áreas cársticas e com ocorrência de cavernas são baseadas nas classificações propostas por CECAV (2009, 2018a). Assim, três conceitos são frequentes nas discussões a cerca do tema: região cárstica, província espeleológica e distrito espeleológico. Para a gestão do território considera-se necessário uma revisão conceitual, a fim de definir parâmetros para identifıcação e definição destas áreas cársticas/ espeleológicas. A falta de conceituação objetiva resulta na existência de lacunas na legislação e em instrumentos de gestão específicos que orientem os órgãos ambientais nas esferas federal, estadual e municipal.

A presente pesquisa traz uma discussão teórica, propõe revisão dos conceitos de região cárstica, província espeleológica e distrito espeleológico e oferece contribuições sobre o método de identificação destas áreas no Brasil. Propõe também a definição da região cárstica dos Campos Gerais, assim como um método para quantificar sua potencialidade para ocorrência de cavernas, denominado potencial espeleológico estimado (PEE). Por fim, estabelecida a nova região cárstica, discute se as feições de origem cárstica desenvolvidas em rochas areníticas são consideradas nas políticas públicas e nos processos de licenciamento ambiental, de maneira que garanta a geoconservação deste patrimônio, o uso adequado dos recursos hídricos (sobretudo de mananciais subterrâneos) e prevenção de riscos geoambientais.

\section{Materiais e métodos}

Foram realizadas consultas a publicações científicas (livros, artigos, mapas, anais de eventos), principalmente de obras que tratam sobre a classificação da paisagem cárstica no
Brasil e os conceitos de região cárstica, província espeleológica e distrito espeleológico.

A análise apresentada tem suporte em diversos estudos sobre as feições e processos cársticos não carbonáticos desenvolvidos em quartzoarenitos da Formação Furnas e da subunidade Vila Velha pertencente à Formação Campo Mourão (Grupo Itararé), na região dos Campos Gerais do Paraná e em pequena porção do estado de São Paulo. Com a análise das informações referentes ao registro de cavidades subterrâneas e o potencial para novas ocorrências de cavernas, a partir da revisão conceitual de região cárstica, província espeleológica e distrito espeleológico, definida nesta pesquisa, foi proposta uma estrutura sequencial para a classificação de regiões cársticas e províncias espeleológicas (figura 1).

Para elaboração dos mapas da região cárstica dos Campos Gerais e do distrito cárstico de Ponta Grossa utilizou-se dados em formato shapefile das regiões cársticas brasileiras e áreas com potencial de ocorrência de cavidades naturais subterrâneas no Brasil, disponíveis pelo CECAV, vetores do Instituto Brasileiro de Geografia e Estatística (IBGE) e dados geológicos da Folha Curitiba SG-22 do Serviço Geológico do Brasil - CPRM. Os mapas foram elaborados em ambiente SIG - Sistemas de Informação Geográfica, por meio do programa de uso livre QGIS versão 3.16.

A avaliação do potencial espeleológico estimado (PEE) do distrito cárstico de Ponta Grossa e da região cárstica dos Campos Gerais foi feita a partir dos dados sobre o número total de cavernas conhecidas, área total classificada como de alto potencial espeleológico e a porcentagem de área explorada/prospectada (valor aproximado, obtido a partir de análise de imagens orbitais e registros de prospecção em trabalhos científicos e relatórios de campo).

Para discutir políticas públicas e carste em área de substrato constituído por quartzoarenitos sem cimento carbonático, primeiramente foi realizada análise da ocorrência de levantamentos cárstico/espeleológicos em estudos ambientais para licenciamento de empreendimentos com alto potencial degradador. Esta etapa baseou-se em consultas a plataformas online, de processos 


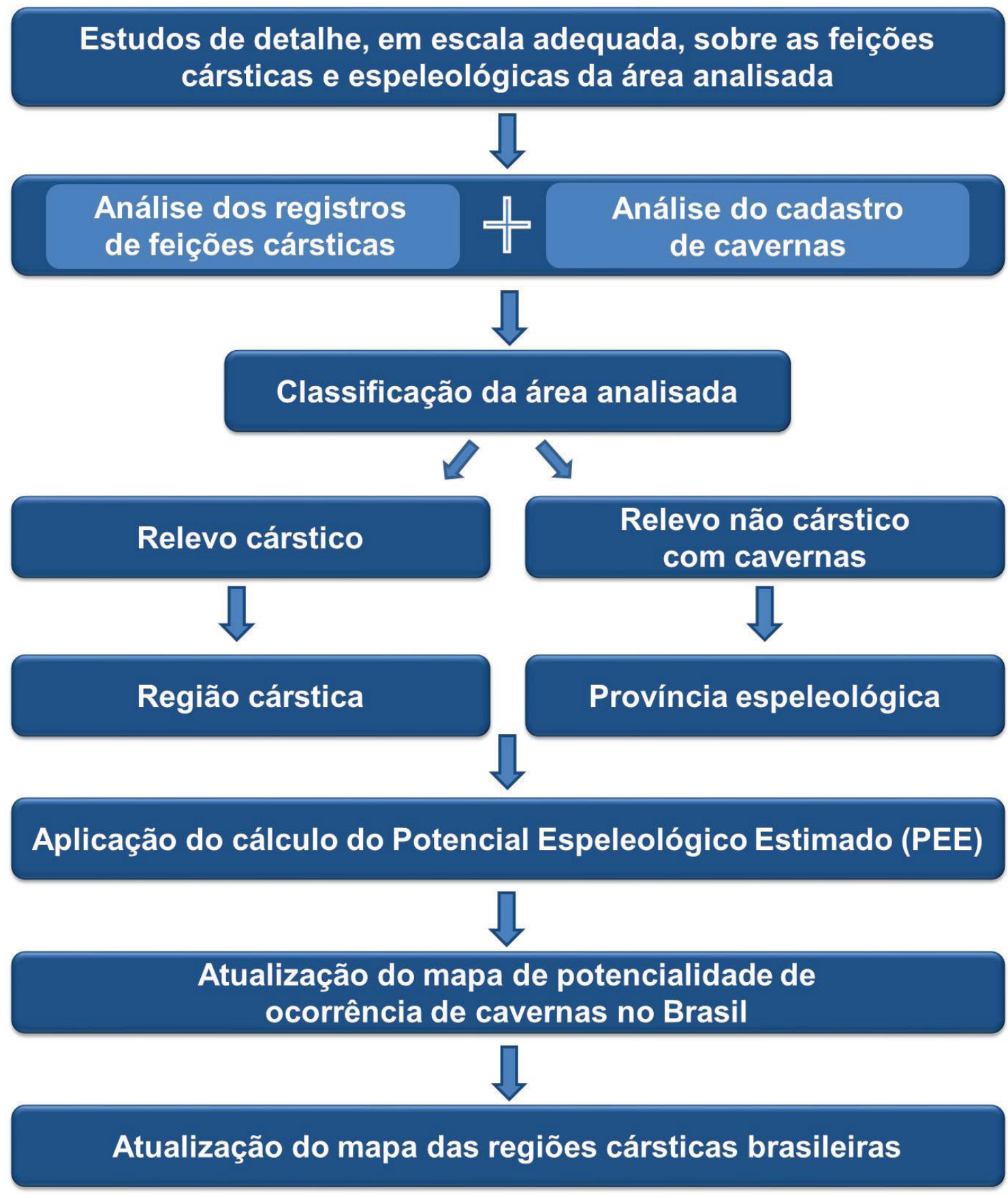

Figura 1. Proposta de procedimentos operacionais para o reconhecimento e classificação de região cárstica e província espeleológica para o Brasil.

Figure 1. Proposal of operational procedures for the recognition and classification of karst region and speleological province in Brazil. 
de licenciamento ambiental disponíveis pelo Instituto Ambiental do Paraná (IAP) e Secretaria Municipal de Meio Ambiente (SMMA) de Ponta Grossa. Foram avaliados Estudos de Impactos Ambientais (EIA), Relatórios Ambientais Simplificados (RAS), Relatórios de Controle Ambiental (RCA), Estudos Prévio de Impactos Ambientais (EPIA) e demais estudos técnicos.

Um levantamento detalhado foi realizado na legislação municipal voltada para o controle do uso e proteção do patrimônio geológico cárstico e espeleológico de Ponta Grossa. Para tanto, utilizou-se as plataformas digitais "leismunicipais.com.br" e "smma.pontagrossa. pr.gov.br/licenciamento/" para pesquisas de leis, decretos, resoluções, decretos legislativos e instruções normativas. Palavras-chave foram aplicadas a fim de direcionar a busca ao tema foco, tais como carste, pseudocarste, espeleologia, caverna, cavidade subterrânea, ressurgência, depressão, espeleotema, água subterrânea, subsolo, entre outras. Após identificação dos dispositivos legais através da busca inicial, a leitura destes documentos legais serviu como um filtro para identificar as leis que tratam sobre o objeto desta pesquisa, para efetuar a análise crítica destes instrumentos.

\section{Resultados}

\subsection{Proposta de revisão de conceitos}

As províncias e distritos espeleológicos foram definidos conceitualmente por Karmann \& Sanchez (1979). No entanto, como apontam Auler et al. (2001) e Auler (2002) estes dois conceitos referem-se exclusivamente à existência de cavidades subterrâneas. Porém, geralmente, as cavernas fazem parte da paisagem cárstica, sendo apenas uma entre várias feições deste tipo de relevo, como depressões no terreno (dolinas), feições ruiniformes, sumidouros, ressurgências. Por este motivo, os autores do presente artigo preferiram utilizar o conceito região cárstica. Todavia, os trabalhos que utilizam a expressão região cárstica não apresentam a definição do conceito. Esta falta gera ambiguidades na sua identificação e classificação.
Define-se neste trabalho que região cárstica deve ser uma unidade de análise para a gestão do território onde ocorrem feições e processos geológicos específicos que exigem cuidados especiais e gestão diferenciada do uso e ocupação do solo. Trata-se de uma área geograficamente delimitada a partir de características litoestratigráficas, composta por uma ou várias unidades geológicas com ou sem constituintes carbonáticos e com presença de relevos cársticos. Pode ser contígua ou não e geralmente de grande extensão territorial (pode ultrapassar limites estaduais). Nestas regiões ocorrem feições cársticas superficiais e subterrâneas, como cavernas, dolinas, redes de drenagens criptorreicas, espeleotemas, espeleogens, relevos ruiniformes e outras geoformas de superfície (depressões fechadas, lapiás, bacias de dissolução, pináculos, alvéolos, relevos ruiniformes).

Áreas com alto potencial espeleológico, mas não classificadas como relevos cársticos, são situações comuns. Por exemplo, as inúmeras cavernas em rochas magmáticas da Ilha de Santa Catarina (Florianópolis-SC) (Mochiutti \& Tomazzoli, 2017; Silva, 2018). Neste contexto, em especial, o conceito de região cárstica não se aplica, por isso a revisão e adequação do conceito de província espeleológica faz-se necessária. Propõe-se que província espeleológica tenha sua definição igual às especificações de região cárstica, contudo aplica-se para áreas desenvolvidas em relevo não cárstico, mas com ocorrência marcante de cavidades naturais subterrâneas, considerando a quantidade de registros.

Os distritos cársticos são áreas de maior concentração de feições cársticas ou apenas cavernas no caso dos distritos espeleológicos, situados dentro de uma região cárstica ou província espeleológica. São desenvolvidos em apenas uma unidade geológica, carbonática ou não. Os distritos ainda podem conter núcleos (cársticos ou espeleológicos), em situação que apresentem concentrações pontuais de feições cársticas ou apenas cavernas em distritos prédefinidos (Fig. 2). 


\subsection{Estudo de caso: o carste não carbonático dos Campos Gerais}

O município de Ponta Grossa, situado na região dos Campos Gerais do Paraná, possui dezenas de cavernas (e.g. Maack, 1956; Melo \& Giannini, 2007; Melo et al., 2015; Pontes et al., 2018a, 2018b). Desenvolveram-se em quartzoarenitos da Formação Furnas e da subunidade Vila Velha (Formação Campo Mourão, do Grupo Itararé). Nesta área há exemplos de sistemas subterrâneos com centenas de metros de desenvolvimento linear, além de grande potencial para novas descobertas espeleológicas.

Diversos estudos apresentaram evidências da atuação de processos de intemperismo químico nos quartzoarenitos, envolvendo dissolução do cimento e dos grãos de quartzo (e.g. Melo \& Giannini, 2007; Melo et al., 2015; Pontes et al., 2018b, Pontes, 2019). Há feições consideradas chave na classificação do relevo sustentado por arenitos quartzosos como cárstico, além das cavernas, depressões no terreno, espeleotemas, rochas arenizadas e fantomizadas, dutos de dissolução, cúpulas, canais de teto e parede (half-tubes) e alvéolos (tafoni) (Pontes et al., 2018b; Pontes, 2019).
Ao analisar toda a área de afloramento destas unidades litoestratigráficas nos Campos Gerais do Paraná e pequena porção do estado de São Paulo, observa-se o registro contínuo de tais feições cársticas, como também de cavidades subterrâneas. Estas ocorrências sustentam a proposição de uma nova região cárstica brasileira que reúne duas unidades geológicas, aqui denominada região cárstica dos Campos Gerais, por ser um nome de reconhecimento por parte da comunidade acadêmica e sociedade em geral em nível regional (figura 3).

\subsection{As áreas com potencial de ocorrência de} cavidades subterrâneas e as regiões cársticas do Brasil: proposta de revisão

Das dezenove regiões cársticas identificadas pelo Centro Nacional de Pesquisas e Conservação de Cavernas (CECAV), quatorze se desenvolvem em rochas carbonáticas, três em rochas siliciclásticas metasedimentares e duas em rochas ferríferas.

No entanto, novas regiões cársticas brasileiras podem ser identificadas, independente do litotipo associado, desde que a região seja definida segundo o critério de ser um relevo

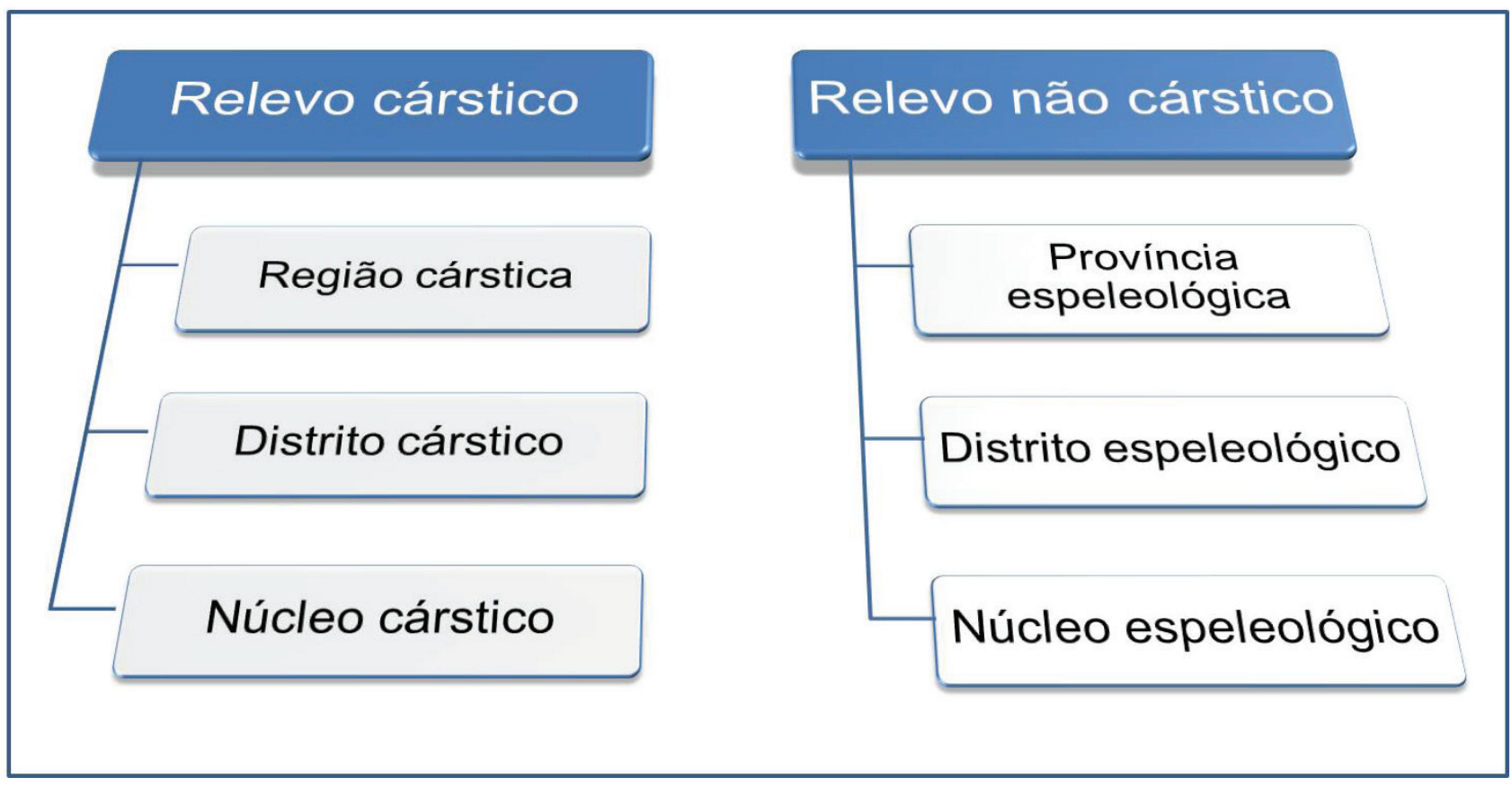

Figura 2. Proposta de classificação de região cárstica e província espeleológica, com base na existência de relevo cárstico (carbonático ou não).

Figure 2. Proposed of karst region and speleological province classification, based on the existence of karst relief (carbonate or not). 
cárstico, com ocorrência de feições geológicas típicas formadas a partir de processos de intemperismo químico, ou seja, apresente processos de carstificação.

A ausência, baixo ou médio potencial de ocorrência de cavidades naturais subterrâneas, classificação adotada por CECAV (2012) para definir o grau de potencialidade de ocorrência de cavernas, não podem ser características limitantes para classificar uma região cárstica, ou até mesmo uma província espeleológica. Devido à elevada extensão territorial brasileira e a pequena quantidade de grupos, profissionais e cientistas da espeleologia, várias áreas ainda não foram devidamente prospectadas e estudadas, a exemplo da região cárstica dos Campos Gerais. Da mesma forma, a existência de rochas carbonáticas também não deve determinar o potencial de ocorrência de cavernas, muito menos ser considerado fator exclusivo para definir áreas cársticas, uma vez que há relevos desenvolvidos em rochas não carbonáticas que superam o número de cavidades registradas em relevos formados em litotipos carbonáticos. Como exemplo, no estado de Santa Catarina, o município com maior ocorrência espeleológica é Florianópolis, cavidades essencialmente formadas em rochas magmáticas (granito, diabásio, riolito e ignimbrito) (Mochiutti \& Tomazzoli, 2017; Silva, 2018).

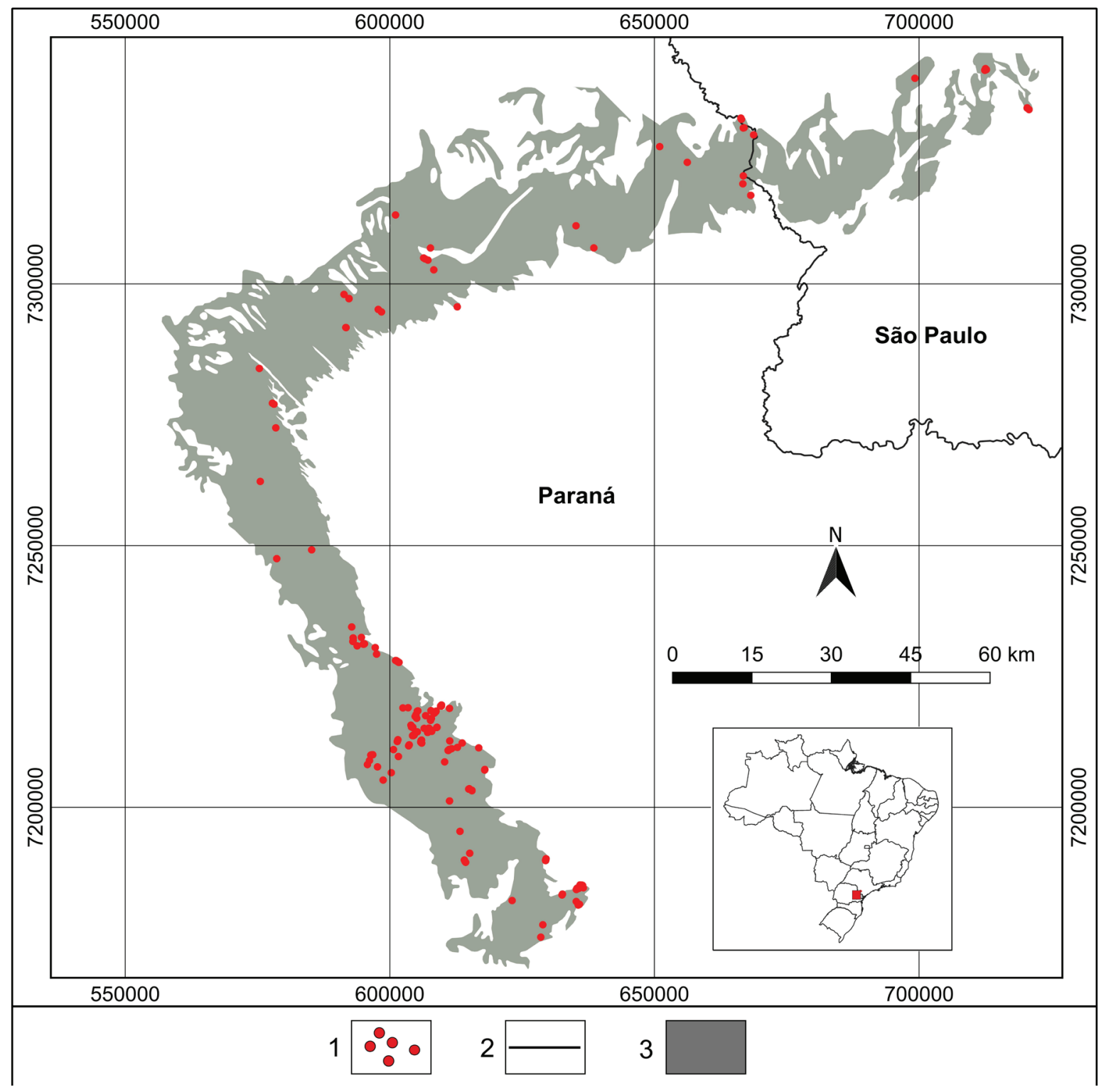

Figura 3. Região cárstica dos Campos Gerais e suas cavidades subterrâneas areníticas. Convenções cartográficas: 1cavernas; 2- limite estadual; 3- limites da RCCG.

Figure 3. Campos Gerais karst region and its sandstone caves. Cartografic conventions: 1- caves; 2- states territorial boundary; 3- CGKR area. 
No ano de 2009, época da elaboração do mapa das regiões cársticas do Brasil (CECAV, 2009), o Cadastro Nacional de Informações Espeleológicas (CANIE) possuía seis mil cavidades subterrâneas cadastradas. No lançamento do mapa de potencialidade espeleológica, elaborado por Jansen et al. (2012), havia 10.476 cavernas brasileiras cadastradas na base de dados do CECAV. Atualmente, de acordo com CANIE (2020) há 21.552 cavernas catalogadas no território nacional, ou seja, menos da metade deste total de cavernas eram conhecidas na época da elaboração do mapa das regiões cársticas brasileiras. Este expressivo aumento no cadastro de cavidades subterrâneas reforça a necessidade de revisões e atualizações nas bases cartográficas das regiões cársticas e províncias espeleológicas brasileiras.

\subsection{Distrito cárstico de Ponta Grossa e seu potencial espeleológico estimado (PEE)}

O distrito cárstico de Ponta Grossa é composto por quartzoarenitos de cimento não carbonático, conforme apontam Melo \& Giannini (2007) e Melo et al. (2015). Possui 122 cavidades naturais subterrâneas, sendo 118 registros na Formação Furnas e quatro na subunidade Arenito Vila Velha (Grupo Itararé) (Quadro 1) (Fig. 4).

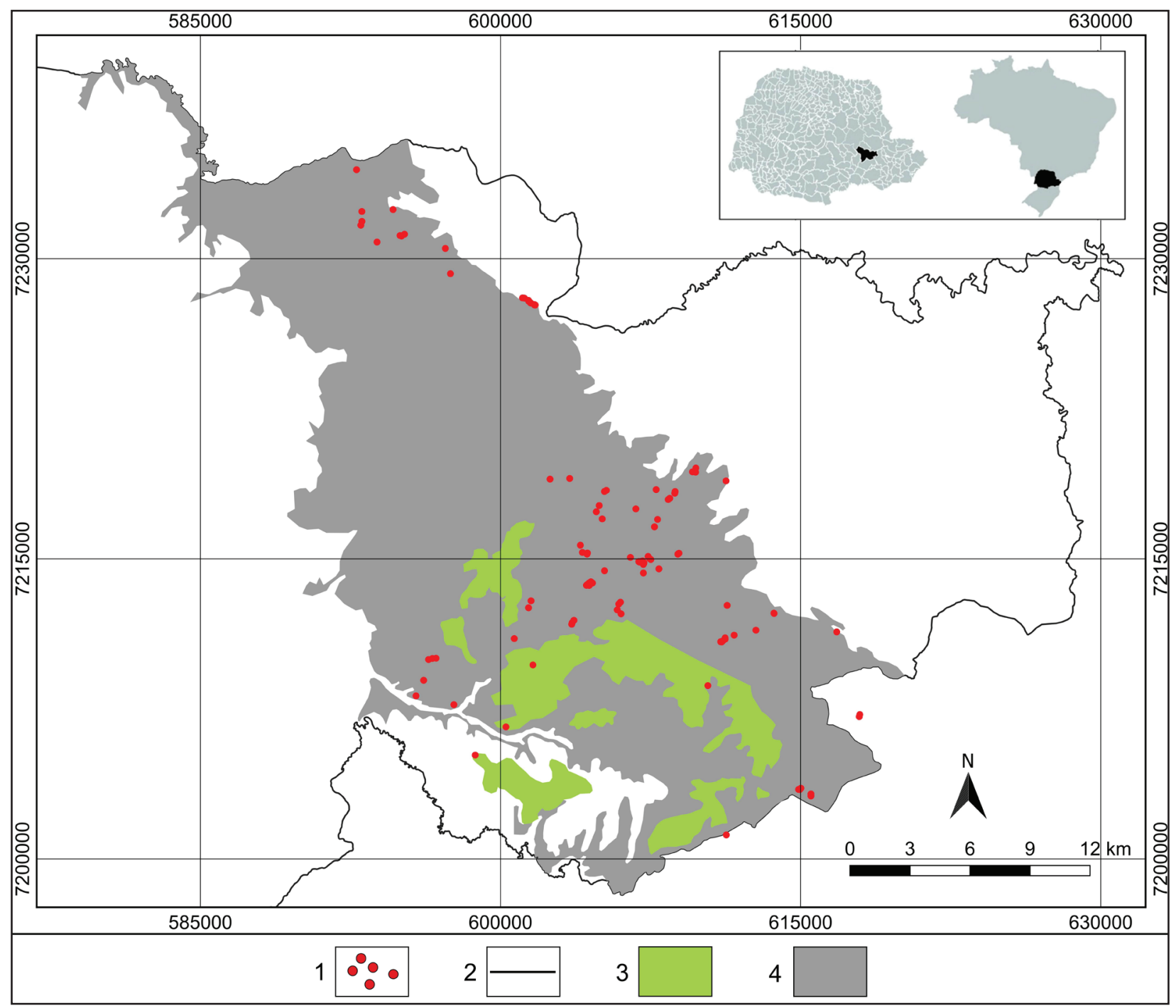

Figura 4. Distribuição das cavidades subterrâneas areníticas do distrito cárstico de Ponta Grossa. Convenções cartográficas: 1- cavernas; 2- limite do município de Ponta Grossa; 3- Grupo Itararé (área de ocorrência do Arenito Vila Velha); 4- Formação Furnas.

Figure 4. Sandstone caves distribution in the Ponta Grossa karst district. Cartographic conventions: 1- caves; 2- limit of the municipality of Ponta Grossa; 3- Grupo Itararé (area of occurrence of the Vila Velha sandstone); 4- Furnas Formation. 
Quadro 1. Cavidades subterrâneas de Ponta Grossa, por unidade geológica.

Chart 1. Ponta Grossa caves, by geological unit.

\begin{tabular}{|c|c|c|c|}
\hline \multicolumn{2}{|r|}{ Formação Furnas } & \multicolumn{2}{|r|}{ Subunidade Vila Velha - Grupo Itararé } \\
\hline 1 & Furna Gêmea 1 & 62 & Gruta dos Opiliões \\
\hline 2 & Furna Gêmea 2 & 63 & Gruta de Cima dos Opiliões \\
\hline 3 & Furna Grande & 64 & Toca do Remexido \\
\hline 4 & Poço das Andorinhas & 65 & Gruta da Chente \\
\hline 5 & Abismo do Haras & 66 & Toca do Bicho I \\
\hline 6 & Buraco do Padre & 67 & Toca do Bicho II \\
\hline 7 & Furna do Bugio & 68 & Toca Mebati \\
\hline 8 & Furna de Vila Velha 1 & 69 & Toca do Corredor \\
\hline 9 & Furna de Vila Velha 2 & 70 & Abrigo da Teima \\
\hline 10 & Furna de Vila Velha 3 & 71 & Toca do Teto Baixo \\
\hline 11 & Furna de Vila Velha 4 & 72 & Abrigo do Bloco Isolado \\
\hline 12 & Sumidouro do Rio Pitangui & 73 & Toca Slickenside \\
\hline 13 & Sumidouro do Córrego das Fendas & 74 & Gruta Fim da Sem Fim \\
\hline 14 & Sumidouro do Rio Quebra-Perna & 75 & Sumidouro do Guarda \\
\hline 15 & Caverna da Chaminé & 76 & Abismo Guabiroba I \\
\hline 16 & Caverna do Opilião & 77 & Abismo Guabiroba II \\
\hline 17 & Gruta da Inspirada & 78 & Abismo Guabiroba III \\
\hline 18 & Caverna do Bugio & 79 & Fenda do Carlos \\
\hline 19 & Caverna das Andorinhas & 80 & Toca do Setor \\
\hline 20 & Gruta da Pedra Grande & 81 & Gruta Passo da Natureza \\
\hline 21 & Fenda da Freira & 82 & Abismo Passo da Natureza \\
\hline 22 & Gruta Macarrão & 83 & Gruta da Águia \\
\hline 23 & Abismo Cercado Grande 1 & 84 & Gruta do Vespaziano \\
\hline 24 & Abismo Cercado Grande 2 & 85 & Toca da Pamonha \\
\hline 25 & Caverna do Zé & 86 & Abrigo Sumidouro I \\
\hline 26 & Gruta do Corujão & 87 & Abrigo Sumidouro II \\
\hline 27 & Gruta Cambiju 2 & 88 & Abrigo Cambiju \\
\hline 28 & Caverna dos Trezentos & 89 & Abrigo do Trono \\
\hline 29 & Fenda dos Tonini & 90 & Abrigo Pitangui \\
\hline 30 & Lagoa Dourada & 91 & Abrigo Usina São Jorge \\
\hline 31 & Lagoa Tarumã & 92 & Toca do Morcego \\
\hline 32 & Fenda Sem Fim & 93 & Abrigo Pitangui II \\
\hline 33 & Abismo da Brisa & 94 & Abrigo do Vale dos Escoteiros \\
\hline 34 & Fenda Guacharos & 95 & Abrigo Macarrão I \\
\hline 35 & Sumidouro da Mariquinha & 96 & Abrigo Macarrão II \\
\hline 36 & Abismo Cercado Grande 3 & 97 & Fenda do Rancho Catavento \\
\hline 37 & Poço de Santa Madalena & 98 & Caverna do Dragão \\
\hline 38 & Gruta Mãe da Divina Graça & 99 & Abrigo Morro do Castelo \\
\hline 39 & Fenda do Mosteiro & 100 & Abrigo Meia Lua \\
\hline 40 & Fenda Santa Maria I & 101 & Fenda dos Dutos \\
\hline 41 & Fenda Santa Maria II & 102 & Sumidouro do Rio Cercado Grande \\
\hline 42 & Furna do Anfiteatro & 103 & Abismo da Chuva \\
\hline 43 & Gruta Nova Holanda & 104 & Gruta dos Quatis \\
\hline 44 & Abismo da Bromélia & 105 & Fenda da Neblina \\
\hline 45 & Dolina do Matador & 106 & Abrigo Santa Bárbara \\
\hline 46 & Gruta da Ricota I & 107 & Abrigo do Perau I \\
\hline 47 & Gruta da Ricota II & 108 & Abrigo do Perau II \\
\hline 48 & Toca do Golpe & 109 & Gruta do Bloco Abatido \\
\hline 49 & Toca do Beco Diagonal & 110 & Fenda da Bebê I \\
\hline 50 & Gruta de Ponta Cabeça & 111 & Fenda da Bebê II \\
\hline 51 & Fenda Pulo do Gato & 112 & Abrigo Inundado \\
\hline 52 & Abismo do Ferla & 113 & Fenda dos Ossos \\
\hline 53 & Toca da Catinga & 114 & Fenda da Brecha \\
\hline 54 & Fenda do Morcego & 115 & Fenda do Padre \\
\hline 55 & Abrigo do Campo Minado & 116 & Furna do Poço Encantado \\
\hline 56 & Gruta do Dengoso & 117 & Gruta da Ressurgência \\
\hline 57 & Gruta dos Três Níveis & 118 & Abismo da Terapia \\
\hline 58 & Gruta Deuzolivre & 119 & Gruta Cambiju 1 \\
\hline 59 & Abrigo das Madeiras & 120 & Gruta da Fortaleza \\
\hline 60 & Abrigo do Sol & 121 & Gruta Andorinhas da Pedra Suspensa \\
\hline 61 & Gruta da Rampa & 122 & Gruta do Araújo \\
\hline
\end{tabular}


As cavernas areníticas deste distrito cárstico podem apresentar centenas de metros de desenvolvimento linear, algumas formam importantes sistemas de drenagem subterrânea, possuem acentuada importância bioespeleológica e arqueológica. Recentes estudos de Pontes et al. (2018a) e Pontes (2019) revelaram grande concentração de cavernas em um núcleo deste distrito, que o permitem caracterizá-lo como o maior núcleo cárstico do Sul do Brasil, considerando-se o número de cavernas por metro quadrado (Pontes et al., 2019). Denominado de sistema de cavernas Fenda Sem Fim, o distrito compreende 25 cavidades naturais subterrâneas, com perspectiva de novos registros espeleológicos.

Mais de um quarto do município de Ponta Grossa possui alto potencial para a ocorrência de cavidades subterrâneas em rochas areníticas quartzosas (Tab. 1). No entanto, em apenas 16,4\% do total da área com potencialidade elevada foi realizada exploração espeleológica de detalhe.

Piló \& Auler (2009) e Jansen et al. (2012) propuseram a estimativa geral do potencial espeleológico a partir da quantidade conhecida de cavernas. No entanto, os autores não expuseram métodos de cálculo matemático para as estimativas. Recentemente,
Auler (2019) apresentou uma estimativa do potencial espeleológico brasileiro em rochas carbonáticas, siliciclásticas (sedimentares e metassedimentares) e ferríferas, com base no número de cavernas conhecidas, área total de afloramentos, densidades (mínima, média e máxima) de ocorrência de cavidades, área total prospectada e percentual de afloramento. Com o objetivo de se obter um valor numérico para o potencial espeleológico do distrito cárstico arenítico de Ponta Grossa, propõe-se aqui um algoritmo para o cálculo do potencial espeleológico estimado (PEE).

O método de cálculo utiliza a relação entre o número de cavernas conhecidas (feita separadamente, avaliando por unidade geológica ou de modo agrupado), e a área total classificada como de alto potencial espeleológico (área total de afloramentos rochosos, podendo ser realizada baseando-se nas compartimentações região/ província, distrito ou núcleo) e a porcentagem de área explorada (área conhecida até o momento, onde foi realizada prospecção espeleológica, em hectares ou metros/quilômetros quadrados). Assim, propõe-se a seguinte equação, que aplicada ao distrito cárstico de Ponta Grossa, gerou os resultados apresentados na tabela 2.

Tabela 1. Área do distrito cárstico de Ponta Grossa e relação com as porções exploradas, valores por unidade geológica e total.

Table 1. Area of the Ponta Grossa karst district and relation with the explored portions, values per geological and total unit.

\begin{tabular}{cccc}
\hline Unidade geológica & $\begin{array}{c}\text { Área (ha) com } \\
\text { alto potencial } \\
\text { espeleológico }\end{array}$ & $\begin{array}{c}\text { Área explorada } \\
\text { aproximada (ha) }\end{array}$ & $\begin{array}{c}\text { Área explorada } \\
\text { (\% aproximada) }\end{array}$ \\
\hline Arenito Vila Velha & 6.449 & 2.235 & 34,6 \\
Formação Furnas & 56.600 & 8.119 & 14,3 \\
Área total & 63.049 & 10.354 & 16,4 \\
\hline
\end{tabular}

Tabela 2. Potencial espeleológico estimado do distrito cárstico de Ponta Grossa, por unidade geológica. Table 2. Estimated speleological potential of the Ponta Grossa karst district, by geological unit.

\begin{tabular}{ccc}
\hline Unidade geológica & $\begin{array}{c}\mathbf{N}^{\circ} \text { de cavidades } \\
\text { conhecidas }\end{array}$ & $\begin{array}{c}\text { Possível PEE (cavidades } \\
\text { não conhecidas) }\end{array}$ \\
\hline Arenito Vila Velha & 4 & $>11$ \\
Formação Furnas & 118 & $>825$ \\
Total & 222 & $>836$ \\
\hline
\end{tabular}




$$
P E E=\frac{100 x C A V c}{\% P E \exp }
$$

Onde:

PEE = potencial espeleológico estimado $\mathrm{CAVc}=$ quantidade de cavernas conhecidas PEexp = porcentagem da área total explorada em relação a área total com potencial espeleológico

Em relação aos valores atribuídos à área com potencial espeleológico e área total explorada, pode ser adotado qualquer padrão de medida (hectares, quilômetros quadrados, metros quadrados). Contudo, para identificar PEexp (porcentagem da área total explorada em relação a área total com potencial espeleológico) o padrão de medida desses valores deve ser o mesmo.

Sem o número de cavernas conhecidas e sem o valor (ao menos aproximado) do quanto (em porcentagem) foi explorada/prospectada a área em análise, não é possível determinar o PEE. Da mesma forma, a combinação de baixa ocorrência de cavidades e pouca área explorada pode gerar valores incompatíveis com a realidade. Uma área com potencial espeleológico não necessariamente contém muitas cavernas. Por isso, informações qualitativas são necessárias, uma vez que, por exemplo, determinadas condicionantes geológicas (grau elevado de metamorfismo, relevo ou ausência de estruturas tectônicas/permeabilidade por fratura) podem ser fatores decisivos para a ausência ou raridade de cavernas.

O Arenito Vila Velha tem ocorrência restrita ao distrito cárstico de Ponta Grossa. Por outro lado, a Formação Furnas compõe praticamente toda a região cárstica dos Campos Gerais e tem apresentado alto potencial espeleológico. A escassez de informações ainda existente em áreas sobre estas rochas nesta região cárstica permite supor que há inúmeras cavidades subterrâneas não conhecidas. Ao estender os cálculos do potencial espeleológico estimado (PEE) para toda a região cárstica dos Campos Gerais o resultado mostra um potencial para a existência de nove mil cavernas, conforme apresenta a tabela 3.

Os trabalhos desenvolvidos por Massuqueto \& Pontes (2017) e Pontes etal. (2019) validaram o cálculo do Potencial Espeleológico Estimado no distrito cárstico de Ponta Grossa ao evidenciar a real ocorrência de cavernas na área em questão. Massuqueto \& Pontes (2017) realizaram prospecção percorrendo apenas um quilômetro linear no front da Escarpa Devoniana e identificaram dez novas cavidades, destacando que a escarpa tem uma extensão total de 260 quilômetros linear. Pontes et al. (2019) também reafirmaram o potencial espeleológico previsto para o distrito cárstico de Ponta Grossa ao identificarem 25 cavidades naturais subterrâneas no sistema de cavernas Fenda Sem Fim, que corresponde a uma área com aproximadamente quatro hectares.

Destaca-se que o potencial espeleológico significa a suscetibilidade de existir, mas sem existência confirmada. Ou seja, o PEE deve ser validado através de prospecções espeleológicas em todas as situações em que for utilizado, com base em demonstração estatística. Do contrário, os resultados serão especulativos, baseados apenas em informações presentes na literatura, nos bancos de dados e demais fontes disponíveis.

Tabela 3. Potencial espeleológico estimado da região cárstica dos Campos Gerais.

Table 3. Estimated speleological potential of the Campos Gerais karst region.

\begin{tabular}{ccccc}
\hline $\begin{array}{c}\text { Área (ha) com } \\
\text { alto potencial } \\
\text { espeleológico }\end{array}$ & $\begin{array}{c}\text { Área explorada } \\
\text { aproximada (ha) }\end{array}$ & $\begin{array}{c}\text { Área explorada } \\
\text { (\% aproximada) }\end{array}$ & $\begin{array}{c}\mathbf{N}^{\circ} \text { de cavidades } \\
\text { conhecidas }\end{array}$ & $\begin{array}{c}\text { Possível PEE } \\
\text { (cavidades não } \\
\text { conhecidas) }\end{array}$ \\
\hline $465.005,67$ & 12.577 & 2,70 & 243 & 9000 \\
\hline
\end{tabular}




\section{Discussão}

\subsection{Carste em áreas de rochas não carbonáticas e políticas públicas}

A geoconservação de áreas cársticas no Brasil é um desafio de décadas. A Constituição Federal de 1988 e o Decreto no 99.556, de $1^{\circ}$ de outubro de 1990 (BRASIL, 1988, 1990), são considerados marcos fundamentais para a conservação do patrimônio espeleológico brasileiro. Contudo, o Decreto n 6.640, de 7 de novembro de 2008 (BRASIL, 2008), modificou toda a referência de proteção das cavernas no território nacional. Antes do Decreto $n^{0}$ 6.640/2008, qualquer cavidade natural subterrânea não poderia ser suprimida ou ser submetida a impactos negativos irreversíveis devido a um empreendimento ou atividade qualquer. Após este marco legal de 2008 as cavernas perderam o status de totalmente protegidas, e passaram para uma situação de até possível supressão total.

Atualmente, o processo de licenciamento espeleológico e a determinação do grau de relevância das cavernas são definidos pela Instrução Normativa MMA n 02 , de 30 de agosto de 2017 (MMA, 2017). Cavernas classificadas como de máxima relevância, teoricamente, não podem ser suprimidas. As definidas como de alta relevância podem ser totalmente destruídas, desde que ocorra compensação espeleológica, e outras duas cavidades de alta relevância devem ser protegidas. As qualificadas como de média e baixa relevância podem ser eliminadas sem a necessidade de nenhum tipo de compensação ambiental.

Entretanto, os principais dispositivos legais que tratam sobre as cavidades subterrâneas não deixam claro que para o licenciamento de todo e qualquer empreendimento e atividade que possa causar dano ao patrimônio cárstico e espeleológico, deve ser realizada exploração e prospecção espeleológica adequada, conforme método apontado por Moura (2013). Segundo o autor, os levantamentos devem envolver avaliação prévia do potencial espeleológico, determinação da densidade da malha de prospecção e percentual amostral a ser atingido em cada área. Em campo, a exploração deve ter como objetivo identificar feições cársticas superficiais e subterrâneas, incluindo cavernas, dolinas, sumidouros, ressurgências, afloramentos com feições ruiniformes diversas, entre outras. Todo o caminhamento durante o trabalho de exploração deve ser registrado com GPS (Global Position System) e salvo em arquivos GPX (GPS Exchange Format), como prova do efetivo trabalho de campo segundo os parâmetros adotados no método de prospecção. Contudo, o que comumente se faz nos estudos de licenciamento ambiental reduz-se apenas a consulta da existência ou não de registro de cavernas no Cadastro Nacional de Informações Espeleológicas (CANIE), e os trabalhos de campo para a investigação de novas cavidades não são executados.

Nenhuma legislação recomenda ou indica uma base cartográfica de referência para a identificação de áreas com ocorrência de cavernas, de potencial para o desenvolvimento de outras feições cársticas, das regiões cársticas, das províncias espeleológicas e seus distritos e núcleos. Mesmo havendo mapas com estes temas, apresentados pelo CECAV, não são documentos anexos ou reconhecidos por leis, ou seja, não possuem valor jurídico.

As regiões cársticas são compostas não somente por cavernas, mas também por um conjunto de feições geológicas e a legislação ambiental em vigor não é abrangente o suficiente para prever legalmente estas outras feições geológicas de origem cárstica, além das cavidades. Quando se trata de feições cársticas em áreas não carbonáticas, como exemplo, em quartzoarenitos, a legislação tornase mais ineficiente, não reconhecendo a própria existência de processos cársticos nestes tipos de relevo, ou deixando brandas as restrições e exigências. Conforme CECAV (2012), o mapa de potencialidade de ocorrência de cavernas no Brasil aponta que a área reconhecida neste artigo como a região cárstica dos Campos Gerais possui médio potencial espeleológico, contrapondo-se ao fato de Ponta Grossa ser um dos municípios que mais possui cavernas no país e o potencial espeleológico estimado desta região apontar para a possibilidade da existência de nove mil 
cavernas.

0 Decreto $n^{0}$ 6.640, de 7 de novembro de 2008, no $\S 3^{\circ}$ de seu Art. 14 (BRASIL, 2008), usa a palavra "pseudocarste" para se referir a relevo que congrega dolinas, sumidouros, ressurgências, vales cegos, lapiás e cavernas. Este termo foi outrora utilizado no meio acadêmico, mas na atualidade é considerado ultrapassado (Hardt, 2011) e causa mais ambiguidade do que efetivamente esclarece sobre os processos cársticos e suas formas e feições de relevo em rochas carbonáticas e não carbonáticas. A carstificação pode ocorrer em rochas sem nenhum componente carbonático conforme documentado por vários autores (e.g. Rodet, 2014; Sauro, 2014; Wray \& Sauro, 2017), de maneira que o relevo desenvolvido nestas podem ser classificados como cársticos.

As lacunas existentes na legislação nacional acerca das áreas cársticas não carbonáticas e suas feições geológicas têm reflexo nos procedimentos administrativos de órgãos ambientais estaduais e municipais, assim como nos processos de licenciamento ambiental. Como destacado por Pontes \& Massuqueto (2016), o antigo Instituto Ambiental do Paraná (IAP), atual Instituto Água e Terra (IAT), não exige levantamentos espeleológicos de detalhe para a instalação de empreendimentos que causam significativo impacto ambiental, sobretudo em áreas com ausência de rochas carbonáticas, como a região cárstica abordada nesta pesquisa. Os autores avançam nas discussões e salientam que a prática adotada pelo referido instituto é apenas exigir que o empreendedor indique ou não a ocorrência de cavidades subterrâneas, sem nenhum estudo aprofundado, nem laudo, parecer ou relatório de profissionais especializados.

Ao analisar os processos de licenciamento ambiental do IAT verifica-se que grandes empreendimentos e atividades geradoras de impactos diretos à região cárstica dos Campos Gerais não apresentaram estudos suficientes, nem utilizam de métodos adequados, envolvendo prospecção e caracterização cárstica/espeleológica. Há situações em que não há palavras relacionadas ao tema (por exemplo: cavernas, cavidades, espeleologia, carste) nos documentos, o que demonstra a total exclusão do assunto nestes estudos.

O quadro 2 apresenta os estudos ambientais de empreendimentos a serem, ou já instalados, na região cárstica dos Campos Gerais, em situação inadequada, conforme comentado.

Salienta-se que foi identificado o Estudo de Impacto Ambiental (EIA) de apenas um empreendimento de mineração na plataforma online do IAT. Contudo, consultas realizadas ao Sistema de Informações Geográficas da Mineração (SIGMINE), informações disponíveis pela Agência Nacional de Mineração (ANM, 2019), mostram que há oito processos em fase de concessão de lavra de areia por desmonte mecânico de rocha arenítica na região cárstica dos Campos Gerais.

Desde o ano de 2013, há um processo de descentralização do licenciamento ambiental no estado do Paraná. Tal modificação foi estabelecida na tentativa de diminuir a elevada demanda existente sobre o Instituto Água e Terra (IAT), que mesmo com um quadro de servidores defasado em relação ao número de técnicos e capacidade de processamento, recebe alta quantidade de pedidos de licenças ambientais. Assim, o Conselho Estadual de Meio Ambiente do Paraná (CEMA) publicou a Resolução CEMA n 088, de 27 de agosto de 2013, que "estabelece critérios, procedimentos e tipologias para o licenciamento ambiental municipal de atividades, obras e empreendimentos que causem ou possam causar impacto de âmbito local" (CEMA, 2013).

Esta resolução possibilita que o licenciamento ambiental passe a ser administrado por instâncias municipais, por órgão municipal capacitado e com estrutura física básica, necessária para o bom desenvolvimento dos trabalhos. Porém, nem sempre este requisito é atendido, a exemplo do município de Ponta Grossa, que utiliza recursos do Fundo Municipal de Defesa do Meio Ambiente (FUNDAM) para equipar e estruturar a Secretaria Municipal de Meio Ambiente, mesmo não havendo disposição em lei autorizando tal ação, conforme informações presentes nas ATAS do Conselho Municipal de Meio Ambiente - COMDEMA (SMMA, 2021). 
Quadro 2. Análise da ausência de levantamentos cárstico/espeleológicos em estudos ambientais para licenciamento de empreendimentos com alto potencial degradador na região cárstica dos Campos Gerais.

Chart 2. Analysis of the absence of karst and speleological surveys in studies for environmental licensing of undertakings with high degrading potential in the Campos Gerais karst region.

\begin{tabular}{|c|c|c|c|}
\hline Empreendimento & Município & $\begin{array}{c}\text { Levantamentos } \\
\text { cárstico/espeleológicos } \\
\text { realizados } \\
\end{array}$ & Documento de referência \\
\hline UHE de Telêmaco Borba & Tibagi & Apenas consulta ao CANIE & $\begin{array}{c}\text { Estudo de Impacto } \\
\text { Ambiental (EIA) - SOMA } \\
(2011)\end{array}$ \\
\hline PCH Castro & Castro & Nenhum & $\begin{array}{c}\text { EPIA - Estudo Prévio de } \\
\text { Impacto Ambiental (EPIA) - } \\
\text { IGPLAN (2010) }\end{array}$ \\
\hline PCH Fortaleza & Tibagi & Nenhum & $\begin{array}{c}\text { Estudo de Impacto } \\
\text { Ambiental (EIA) - AMÜLLER } \\
\text { (2014) }\end{array}$ \\
\hline UHE Santa Branca & $\begin{array}{l}\text { Tibagi e } \\
\text { Carambeí }\end{array}$ & Apenas consulta ao CANIE & $\begin{array}{l}\text { Estudo de Impacto } \\
\text { Ambiental (EIA) - } \\
\text { TITANIUM (2015) }\end{array}$ \\
\hline UHE Tibagi Montante & Tibagi & $\begin{array}{c}\text { Consulta ao mapa de } \\
\text { potencialidade de ocorrência de } \\
\text { cavernas no Brasil }\end{array}$ & $\begin{array}{c}\text { Estudo de Impacto } \\
\text { Ambiental (EIA) - SOMA } \\
\text { (2013) }\end{array}$ \\
\hline Parque Eólico Batavo & Carambeí & Apenas consulta ao CANIE & $\begin{array}{c}\text { Estudo de Impacto } \\
\text { Ambiental (EIA) - Biometria } \\
\text { (2015) }\end{array}$ \\
\hline $\begin{array}{l}\text { Complexo Eólico-Elétrico } \\
\text { Campos Gerais }\end{array}$ & Tibagi & Nenhum & $\begin{array}{c}\text { Estudo de Impacto } \\
\text { Ambiental (EIA) - LACTEC } \\
\text { (2014) }\end{array}$ \\
\hline $\begin{array}{l}\text { Linha de Transmissão de } \\
\text { Energia } 525 \text { kV Ponta } \\
\text { Grossa - Bateias (C1 e C2) }\end{array}$ & $\begin{array}{l}\text { Castro, } \\
\text { Carambeí e } \\
\text { Tibagi }\end{array}$ & Nenhum & $\begin{array}{c}\text { Estudo de Impacto } \\
\text { Ambiental (EIA) - } \\
\text { GEOCONSULTORES (2018) }\end{array}$ \\
\hline $\begin{array}{l}\text { Lavra e beneficiamento de } \\
\text { Areia Quartzosa }\end{array}$ & $\begin{array}{l}\text { Ponta } \\
\text { Grossa }\end{array}$ & $\begin{array}{l}\text { Estudo espeleológico parcial, com } \\
\text { prospecção incompleta }\end{array}$ & $\begin{array}{c}\text { Estudo de Impacto } \\
\text { Ambiental (EIA) - } \\
\text { GEOPLANEJAMENTO (2016) }\end{array}$ \\
\hline CGH São João & Carambeí & Apenas consulta ao CANIE & $\begin{array}{l}\text { Relatório Ambiental } \\
\text { Simplificado (RAS) - } \\
\text { RECITECH (2016) }\end{array}$ \\
\hline CGH Rio do Salto e LT & Palmeira & $\begin{array}{l}\text { Apenas consultas ao CANIE e ao } \\
\text { mapa de potencialidade de } \\
\text { ocorrência de cavernas no Brasil }\end{array}$ & $\begin{array}{c}\text { Relatório Ambiental } \\
\text { Simplificado (RAS) - CIA } \\
\text { AMBIENTAL (2017) }\end{array}$ \\
\hline PCH Beira Rio & $\begin{array}{l}\text { Jaguariaíva } \\
\text { e Sengés }\end{array}$ & Nenhum & $\begin{array}{c}\text { Estudo de Impacto } \\
\text { Ambiental (EIA) - AMÜLLER } \\
(2016)\end{array}$ \\
\hline PCH Macacos & $\begin{array}{l}\text { Jaguariaíva } \\
\text { e Sengés }\end{array}$ & Nenhum & $\begin{array}{l}\text { Relatório Ambiental } \\
\text { Simplificado (RAS) - } \\
\text { AMÜLLER (2016) }\end{array}$ \\
\hline $\begin{array}{c}\text { Linha de Transmissão LT } \\
\text { 23KV Figueira/ } \\
\text { Ponta Grossa }\end{array}$ & $\begin{array}{c}\text { Tibagi, } \\
\text { Castro, } \\
\text { Carambeí e } \\
\text { Ponta } \\
\text { Grossa } \\
\end{array}$ & Nenhum & $\begin{array}{l}\text { Relatório Ambiental } \\
\text { Simplificado (RAS) - IG } \\
\text { TRANSMISSÃO E } \\
\text { DISTRIBUIÇÃO (2015) }\end{array}$ \\
\hline $\begin{array}{c}\text { Trecho de LT entre a } \\
\text { subestação Castro Norte e } \\
\text { o seccionamento da LT } 230 \\
\text { KV Klacel - Ponta Grossa } \\
\text { Norte }\end{array}$ & Castro & Apenas consulta ao CANIE & $\begin{array}{l}\text { Relatório Ambiental } \\
\text { Simplificado (RAS) - } \\
\text { AMBIOTECH (2018) }\end{array}$ \\
\hline $\begin{array}{c}\text { Central de Tratamento de } \\
\text { Resíduos Furnas } \\
\text { (CTR/Furnas) }\end{array}$ & $\begin{array}{l}\text { Ponta } \\
\text { Grossa }\end{array}$ & Nenhum & $\begin{array}{c}\text { Estudo de Impacto } \\
\text { Ambiental (EIA) - RESITEC } \\
(2007)\end{array}$ \\
\hline
\end{tabular}


Quadro 3. Legislação de Ponta Grossa que trata, de maneira direta ou indireta, do controle do uso e proteção do patrimônio geológico cárstico e espeleológico municipal.

Chart 3. Ponta Grossa legislation that deals with, directly or indirectly, about the control of the use and protection of the municipal karst geological heritage.

\begin{tabular}{|c|c|}
\hline Dispositivo legal & Finalidade \\
\hline $\begin{array}{l}\text { Decreto } n \text { ㅇ } 13.957 / 2018 \\
\text { (PMPG, 2018a) }\end{array}$ & $\begin{array}{l}\text { Define como competência da Secretaria Municipal de Meio } \\
\text { Ambiente o monitoramento do subsolo }\end{array}$ \\
\hline $\begin{array}{l}\text { IN SMMA n 1-001/2017 } \\
\text { (SMMA, 2017a) }\end{array}$ & $\begin{array}{c}\text { Define estudos específicos para o licenciamento ambiental } \\
\text { de extração mineral em áreas cársticas com ocorrência de } \\
\text { cavernas }\end{array}$ \\
\hline $\begin{array}{l}\text { IN SMMA n } 1-002 / 2017 \\
\text { (SMMA, 2017b) }\end{array}$ & $\begin{array}{c}\text { Define estudos específicos para o licenciamento ambiental } \\
\text { de extração de pedras irregulares de modo artesanal em } \\
\text { áreas cársticas com ocorrência de cavernas }\end{array}$ \\
\hline $\begin{array}{l}\text { IN SMMA n²-001/2017 } \\
\text { (SMMA, 2017c) }\end{array}$ & $\begin{array}{l}\text { Estabelece que atividade de suinicultura não pode se situar } \\
\text { em áreas com afloramentos rochosos e com afloramento } \\
\text { do lençol freático }\end{array}$ \\
\hline $\begin{array}{l}\text { IN SMMA n 10-001/2017 } \\
\text { (SMMA, 2017d) }\end{array}$ & $\begin{array}{l}\text { Estabelece laudo geológico para o licenciamento ambienta } \\
\text { de loteamentos }\end{array}$ \\
\hline $\begin{array}{l}\text { IN SMMA n }{ }^{\circ} 10-002 A / 2017 \\
\text { (SMMA, 2017e) }\end{array}$ & $\begin{array}{l}\text { Estabelece a caracterização geológica no licenciamento } \\
\text { ambiental de implantação de conjuntos habitacionais }\end{array}$ \\
\hline $\begin{array}{l}\text { Decreto } n=10.996 / 2016 \\
\quad(P M P G, 2016)\end{array}$ & $\begin{array}{l}\text { Regulamenta o licenciamento ambiental municipal, } \\
\text { exigindo EIA/RIMA para empreendimentos que } \\
\text { apresentem risco ao patrimônio espeleológico e geológico }\end{array}$ \\
\hline $\begin{array}{l}\text { Lei no } 12.128 / 2015 \\
\text { (PMPG, 2015a) }\end{array}$ & $\begin{array}{l}\text { Cita de maneira equivocada que a captação de água subterrânea } \\
\text { no aquífero "karst" não se enquadra como atividade de potencia } \\
\text { poluidor }\end{array}$ \\
\hline $\begin{array}{l}\text { Lei no } 12.192 / 2015 \\
\quad \text { (PMPG, 2015b) }\end{array}$ & $\begin{array}{l}\text { Inclui o conceito de geodiversidade na política do } \\
\text { ecoturismo e do turismo sustentável na cidade de Ponta } \\
\text { Grossa }\end{array}$ \\
\hline $\begin{array}{l}\text { Lei } n=12.342 / 2015 \\
\text { (PMPG, 2015c) }\end{array}$ & Considera de interesse municipal as águas subterrâneas \\
\hline $\begin{array}{c}\text { Decreto no 8.060/2013 } \\
\text { (PMPG, 2013) }\end{array}$ & $\begin{array}{c}\text { Estabelece a mesma competência ao COMDEMA } \\
\text { apresentada na Lei no 11.233/2012 }\end{array}$ \\
\hline $\begin{array}{l}\text { Lei no } 11.233 / 2012 \\
\text { (PMPG, 2012) }\end{array}$ & $\begin{array}{c}\text { Estabelece que uma das competências do Conselho } \\
\text { Municipal de Meio Ambiente (COMDEMA) é propor a } \\
\text { criação de unidade de conservação para proteção de sítios } \\
\text { espeleológicos }\end{array}$ \\
\hline $\begin{array}{l}\text { Lei no } 10.417 / 2010 \\
\quad \text { (PMPG, 2010) }\end{array}$ & $\begin{array}{l}\text { Dispõe que lençóis de água subterrânea deverão distar, no } \\
\text { mínimo, 2,00m, do ponto mais profundo utilizado para } \\
\text { covas ou jazigos em cemitérios }\end{array}$ \\
\hline $\begin{array}{l}\text { Lei } n=8.473 / 2006 \\
\text { (PMPG, 2006) }\end{array}$ & $\begin{array}{l}\text { Aponta a possível exigência de laudo geológico para } \\
\text { licenciamento na Área de Proteção Ambiental da Floresta } \\
\text { de Araucária do Município de Ponta Grossa - APA }\end{array}$ \\
\hline $\begin{array}{l}\text { Decreto } \mathrm{n}=568 / 2005 \\
\quad \text { (PMPG, 2005) }\end{array}$ & $\begin{array}{c}\text { Estabelece a mesma competência ao COMDEMA } \\
\text { apresentada na Lei no } 11.233 / 2012\end{array}$ \\
\hline $\begin{array}{l}\text { Lei no } 7.636 / 2004 \\
\text { (PMPG, 2004) }\end{array}$ & $\begin{array}{c}\text { Estabelece a mesma competência ao COMDEMA } \\
\text { apresentada na Lei no } 11.233 / 2012\end{array}$ \\
\hline
\end{tabular}


Em Ponta Grossa, a Lei 12.345, de 20 de novembro de 2015, instituiu o Sistema Municipal de Licenciamento e Fiscalização Ambiental, atribuindo à Secretaria Municipal de Meio Ambiente (SMMA) a competência do licenciamento ambiental dos empreendimentos do município (PMPG, 2015d). Mediante análise da legislação municipal foi identificado um conjunto de 16 dispositivos legais de controle do uso e proteção do patrimônio geológico cárstico e espeleológico de Ponta Grossa, conforme apresentados no quadro 3.

Dentre as 40 atividades que o município de Ponta Grossa tem competência para realizar o licenciamento ambiental, quinze são consideradas passíveis de gerar impactos negativos ao patrimônio geológico cárstico e espeleológico, sendo: 1) cascalheira; 2) extração de pedras irregulares de modo artesanal; 3) supressão de exóticas em Área de Preservação Permanente (APP); 4) loteamentos; 5) implantação de conjuntos habitacionais; 6) postos de combustíveis e retalhistas de combustíveis; 7) tratamento e disposição final de resíduos da construção civil; 8) coletor tronco e rede coletora de esgoto; 9) unidade de tratamento de esgoto; 10) conservação, manutenção e restauração de estrada municipal; 11) terraplanagem; 12) atividades industriais; 13) suinocultura; 14) avicultura e; 15) piscicultura. Apenas duas exigem estudos cársticos e espeleológicos, cascalheira e extração de pedras irregulares de modo artesanal. Contudo, as normativas que regulamentam estas atividades não definem com clareza o que são consideradas áreas cársticas com ocorrência de cavernas no município. Da mesma forma, não são exigidos estudos de exploração e prospecção de detalhe, conforme método proposto por Moura (2013).

O Decreto municipal $n^{0} 14.085$, de 20 de fevereiro de 2018, que dispõe sobre infrações ao meio ambiente e estabelece os procedimentos administrativos para apuração destas infrações (PMPG, 2018b), não exige detalhamento, envolvendo dimensionamento e método de cálculo, das infrações cometidas contra o patrimônio geológico como um todo, incluindo as feições cársticas e espeleológicas. A falta de controle agrava-se quando se considera que os processos de licenciamento ambiental do município de Ponta Grossa não ficam disponíveis para consulta pública na plataforma online, procedimento que contraria o princípio da transparência.

Assim, somando-se com as lacunas existentes no conjunto de leis ambientais municipais, também não são de conhecimento público os detalhes sobre os empreendimentos e atividades licenciadas em Ponta Grossa (tipo, localização, tamanho), nem os estudos ambientais elaborados para o licenciamento, tornando-se difícil o controle, fiscalização e proteção do patrimônio cárstico e espeleológico no distrito de maior destaque da região cárstica dos Campos Gerais.

\subsection{Gestão do território da região cárstica dos Campos Gerais}

Segundo Jansen et al. (2012) o mapa de potencialidade de ocorrência de cavernas do Brasil, na escala 1:2.500.000, constitui-se em importante ferramenta para orientar pesquisas técnico-científicas. Entretanto, este material, em conjunto com o mapa das regiões cársticas, tem como função principal auxiliar os órgãos de fiscalização e licenciamento ambiental, bem como a gestão e políticas públicas voltadas à conservação da geodiversidade, especialmente do patrimônio cárstico e espeleológico nacional.

Uma região cárstica apresenta fragilidades ambientais que exigem gestão diferenciada do território, a fim de evitar acidentes geoambientais e proteger o patrimônio geológico. Nestas condições, as feições de origem cárstica desenvolvidas nos quartzoarenitos da Formação Furnas e subunidade Vila Velha precisam ser consideradas nas políticas públicas e nos procedimentos administrativos de gestão ambiental, buscando garantir a geoconservação.

Neste sentido, os processos de licenciamento ambiental de atividades e empreendimentos diversos devem senortear pelo princípio da precaução e o uso e ocupação do solo devem ser orientados em instrumentos de gestão específicos, como zoneamentos ambientais cársticos e zoneamentos espeleológicos. 
Instrumentos de gestão consolidados também devem incluir as características das regiões cársticas, como planos diretores municipais, planos de gestão de bacias hidrográficas, lei de zoneamento urbano e de uso e ocupação das áreas rurais, planos de manejo de unidades de conservação, entre outros.

Recente diagnóstico do CECAV (2018b) considerou toda a área de afloramento da Formação Furnas e do Arenito Vila Velha (subunidade da Formação Campo Mourão), no distrito cárstico de Ponta Grossa, como prioritária para a conservação do patrimônio espeleológico. Além disso, a área foi classificada na categoria 1, demandando principalmente ações voltadas para a criação ou ampliação de unidades de conservação, fiscalização e monitoramento e educação ambiental e patrimonial.

Esta classificação baseou-se exclusivamente na ocorrência concentrada de cavidades subterrâneas neste distrito cárstico. Contudo, conforme já apontado, esta situação se deve à existência e atuação de um grupo de espeleologia, espeleólogos e pesquisadores nesta área. Há outras porções da região cárstica dos Campos Gerais que ainda não foram devidamente exploradas e pesquisadas.

Da mesma forma, os estudos de prospecção e levantamentos espeleológicos devem ser exigências obrigatórias e indispensáveis para o licenciamento ambiental de empreendimentos e atividades com potencial lesividade ao patrimônio geológico cárstico e espeleológico. Segundo o $\S 2^{\circ}$ do Art. 19 do Decreto $n^{\circ}$ 6.640/2008, o empreendedor que requerer licenciamento ambiental deverá realizar previamente o cadastramento das cavidades subterrâneas mencionadas no processo de licenciamento no CANIE. Estes dois condicionamentos resultam no aumento do conhecimento acerca do patrimônio espeleológico nacional. Notável exemplo desta situação é a região cárstica não carbonática da Formação Carajás, que após estudos de licenciamento espeleológico para mineração de ferro, foram descobertas milhares de cavernas na região, patrimônio até então desconhecido (Piló \& Auler, 2009).

\section{Considerações finais}

Regiões cársticas são áreas com características específicas, feições geológicas formadas por processos de intemperismo químico, com fragilidades ambientais que exigem gestão do território e instrumentos que regulem o uso e ocupação do solo. Por este motivo, a classificação das regiões cársticas e províncias espeleológicas brasileiras devem ser baseadas em conceitos bem definidos que assegurem proteção destas áreas.

Assim, estabelecem-seaquidefinições para região cárstica, província espeleológica, distrito e núcleo cárstico/espeleológico. Visa-se, com isto, evitar dúvidas e ambiguidades na caracterização de novas áreas, seja com ocorrência de cavernas, seja em relevos cársticos. Tais redefinições de conceitos têm por objetivo tratá-los como unidades da paisagem, para a gestão do território e para a conservação do patrimônio cárstico e espeleológico brasileiro.

A ausência, baixo ou médio potencial de ocorrência de cavidades naturais subterrâneas não podem ser características limitantes para classificar uma região cárstica, ou até mesmo uma província espeleológica. Com tal objetivo, a pesquisa propõe o indicador de potencial espeleológico estimado (PEE), um algoritmo que pode ter aplicação em várias finalidades, como licenciamentos ambientais, gestão de áreas urbanas e rurais, avaliação do potencial turístico, identificação de áreas prioritárias para a conservação, planos de manejo, zoneamentos ecológico-econômicos, além da possibilidade de servir como base para o desenvolvimento de políticas públicas.

Salienta-se que o PEE não deve ser utilizado como resultado final, mas sim como um instrumento indicativo, devendo ser testado em distintas condições, como em diferentes rochas, condições estruturais, relevos, clima, vegetação. Assim, o presente cálculo de potencial apresenta limitações, e não deve ser o único parâmetro em um levantamento ambiental. A realização de exploração eprospecção espeleológica de detalhe para o licenciamento espeleológico, em toda e qualquer área com ocorrência ou potencialidade espeleológica e cárstica, é exigência prevista em 
decreto federal e deve ser executada.

Análises de detalhe são necessárias em todo o território brasileiro. Com uma base conceitual clara e o uso de escalas adequadas, evitando generalizações e adotando o princípio da precaução, é possível identificar e classificar novas regiões cársticas e províncias espeleológicas. Com estes princípios foi possível caracterizar a RCCG. Contudo, há registros de feições cársticas em áreas de afloramento da Formação Furnas em outros estados do Brasil, o que indica a potencialidade de estabelecimento de novas regiões cársticas.

Há lacunas e ambiguidades na legislação que tratam, de maneira direta ou indireta, do controle do uso e proteção do patrimônio cárstico e espeleológico da RCCG. Os órgãos ambientais licenciadores municipais e estaduais não exigem estudos cárstico/espeleológicos de detalhe como condicionantes para a instalação de empreendimentos de alto impacto ambiental. Este conjunto de circunstâncias coloca em risco o patrimônio geológico em questão.

Para modificação deste panorama sugerem-se as seguintes ações descritas a seguir.

Definição dos conceitos de região cárstica e província espeleológica, destacando a existência de processos cársticos em áreas compostas por rochas não carbonáticas, bem como áreas de alto potencial espeleológico em rochas em que a formação destas feições não é comum, como granitos, gnaisses, riolitos, resultado da falta de prospecção gerada por um contexto histórico nacional de desinteresse da comunidade espeleológica e acadêmica por estas áreas.

Reconhecimento legal dos mapas de regiões cársticas e províncias espeleológicas, de potencialidade de ocorrência de cavernas e das áreas prioritárias para a conservação do patrimônio espeleológico, a fim de atribuir valor jurídico para estes documentos cartográficos. Atualização constante, no máximo a cada dois anos, dos mapas de regiões cársticas e províncias espeleológicas, potencialidade de ocorrência de cavernas e de áreas prioritárias para a conservação do patrimônio espeleológico.

Modificações na legislação federal, estaduais e municipais, incluindo de modo claro e conciso a exigência de exploração e prospecção espeleológica de detalhe, conforme método proposto por Moura (2013), para o licenciamento espeleológico em toda e qualquer área com ocorrência ou potencialidade espeleológica e cárstica, independente do tipo de rocha.

Publicação de documentos de referência para elaboração de estudos cársticos/ espeleológicos para o licenciamento espeleológico por órgãos ambientais estaduais e municipais, seguindo os métodos de levantamentos e orientações apresentados por ICMBIO \& CECAV (2011).

Capacitação dos servidores públicos das esferas federal, estadual e municipal para atuação em licenciamento ambiental espeleológico.

Adoção do princípio da precaução, em todos os casos em que não há registro de feições cársticas/espeleológicas, mas que a área tenha indícios ou potencial para ocorrência.

Aumento do quadro de servidores públicos para atuação em licenciamento ambiental nas diferentes esferas da Federação.

Aumento nos investimentos, por parte do Poder Público, em projetos de pesquisa e formação profissional na área de espeleologia e carstologia.

E por fim, a criação de mecanismos e ações públicas que incentivem e fortaleçam os trabalhos de grupos de espeleologia, com o intuito de aumentar o conhecimento sobre o patrimônio cárstico/espeleológico brasileiro.

Agradecimentos. O primeiro autor agradece à Coordenação de Aperfeiçoamento de Pessoal de Nível Superior (CAPES) pela concessão de bolsa de doutorado (Processo de número 1554618). Todos os autores estendem os sinceros agradecimentos aos revisores, pelas significativas contribuições que resultou no amadurecimento das discussões apresentadas neste artigo.

\section{Referências}

Ambiotech. Consultoria Ambiental. 2018. Relatório Ambiental Simplificado (RAS) Trecho de LT entre a subestação Castro Norte e o seccionamento da LT 230 KV Klacel - Ponta 
Grossa Norte. In: Instituto Água e Terra - ElARIMA - editais. Disponível em: http://www. iat.pr.gov.br/Pagina/EIA-RIMA. Acesso em 11 fev. 2021.

Amüller. Consultoria Ambiental. 2014. Estudo de Impactos Ambientais PCH Fortaleza. In: Instituto Água e Terra - EIA-RIMA - editais. Disponível em: http://www.iat.pr.gov.br/ Pagina/EIA-RIMA. Acesso em 11 fev. 2021.

Amüller. Consultoria Ambiental. 2016. Estudo de Impactos Ambientais PCH Beira Rio. In: Instituto Água e Terra - EIA-RIMA - editais. Disponível em: http://www.iat.pr.gov.br/ Pagina/EIA-RIMA. Acesso em 11 fev. 2021.

Amüller. Consultoria Ambiental. 2016. Relatório Ambiental Simplificado PCH Macacos. In: Instituto Água e Terra - EIA-RIMA - editais. Disponível em: http://www.iat.pr.gov.br/ Pagina/EIA-RIMA. Acesso em 11 fev. 2021.

ANM. Agência Nacional de Mineração. 2019. Sistema de Informações Geográficas da Mineração - SIGMINE. Disponível em: http:// sigmine.dnpm.gov.br/webmap/. Acesso em 11 fev. 2021.

Auler, A.S. 2020. Karst areas in Brazil and the potential for major caves-an overview. Boletin de la Sociedad Venezolana de Espeleologia, 36: 29-35.

Auler, A.S., Rubbioli, E.L. \& Brandi, R.. As grandes cavernas do Brasil. v. 1. Belo Horizonte: Rona Editora, 2001.

Auler, A.S. 2019. Histórico, ocorrência e potencial de cavernas no Brasil. In: Rubbioli E.L., Auler, A.S., Menin, D.S., Brandi, R (org.). Cavernas. Atlas do Brasil Subterrâneo. Editora IABS, Brasilia, p. 10-47.

Biometria. Consultoria Ambiental. 2015. Estudo de Impactos Ambientais Parque Eólico Batavo. In: Instituto Água e Terra - EIA-RIMA - editais. Disponível em: http://www.iat.pr.gov. br/Pagina/EIA-RIMA. Acesso em 11 fev. 2021.

BRASIL. 1988. Constituição da República Federativa do Brasil. Disponível em: http:// www.planalto.gov.br/ccivil_03/constituicao/ constituicaocompilado.htm. Acesso em 11 fev. 2021.

BRASIL. 1990. Decreto Federal No 99.556, de $1^{\circ}$ de Outubro de 1990. Disponível em: http:// www2.camara.leg.br/legin/fed/decret/1990/ decreto-99556-1-outubro-1990-339026publicacaooriginal-1-pe.html. Acesso em 11 fev. 2021

BRASIL. 2008. Decreto ${ }^{\circ}$ 6.640, de 7 de novembro de 2008. Disponível em: http://www.planalto. gov.br/ccivil_03/_Ato2007-2010/2008/ Decreto/D6640.htm. Acesso em 11 fev. 2021.

CANIE. Cadastro Nacional de Informações Espeleológicas. 2020. Relatório Estatístico do CANIE. Disponível em: http://www.icmbio.gov. $\mathrm{br} /$ cecav/index.php?option=com_icmbio_cani e\&controller=relatorioestatistico\&itemPesq=tr ue. Acesso em 11 fev. 2021.

CEMA. Conselho Estadual do Meio Ambiente do Paraná. 2013. Resolução CEMAnº 088, de 27 de agosto de 2013. Disponível em: https://www. legislacao.pr.gov.br/legislacao/pesquisarAto. do? action $=$ exibir \&codAto $=101120 \&$ indice $=1 \&$ totalRegistros $=9 \& d t=13.7 .2019 .16 \cdot 29.54 .207$. Acesso em 11 fev. 2021.

CECAV. Centro Nacional de Pesquisa e Conservação de Cavernas. 2009. Mapa das regiões cársticas do Brasil. Disponível em: http://www.icmbio.gov.br/cecav/images/ stories/projetos-e-atividades/regioes_ carsticas/mapa_provincias_espeleo_brasil_ a1_reamostrado.pdf. Acesso em 11 fev. 2021. CECAV. Centro Nacional de Pesquisa e Conservação de Cavernas. 2012. Mapa de potencialidade de ocorrência de cavernas no Brasil. Disponível em: http://www.icmbio. gov.br/cecav/images/stories/projetos-eatividades/mapa_potencialidade_BR_CECAV_ jun12.pdf. Acesso em 11 fev. 2021.

CECAV. Centro Nacional de Pesquisa e Conservação de Cavernas. 2018a. Mapa de áreas de ocorrência de cavernas no Brasil. Disponível em: http://www.icmbio.gov.br/ cecav/projetos-e-atividades/provinciasespeleologicas.html. Acesso em 11 fev. 2021.

CECAV. Centro Nacional de Pesquisa e Conservação de Cavernas. 2018b. Áreas prioritárias para a conservação do patrimônio espeleológico. Disponível em: http://www. icmbio.gov.br/cecav/projetos-e-atividades/ areas-prioritarias-conservacao.html. Acesso em 11 fev. 2021.

Ciaambiental. Consultoria Ambiental. 2017. Relatório Ambiental Simplificado CGH Rio do 
Salto e LT. In: Instituto Água e Terra - EIARIMA - editais. Disponível em: http://www. iat.pr.gov.br/Pagina/EIA-RIMA. Acesso em 11 fev. 2021.

Geoconsultores. Instituto de Tecnologia para o Desenvolvimento. 2018. Estudo de Impactos Ambientais Linha de Transmissão de Energia 525 kV Ponta Grossa - Bateias (C1 e C2). In: Instituto Água e Terra - EIA-RIMA - editais. Disponível em: http://www.iat.pr.gov.br/ Pagina/EIA-RIMA. Acesso em 11 fev. 2021.

Geoplanejamento. Consultoria Ambiental. 2016. Estudo de Impactos Ambientais Lavra e beneficiamento de Areia Quartzosa. In: Instituto Água e Terra - EIA-RIMA - editais. Disponível em: http://www.iat.pr.gov.br/ Pagina/EIA-RIMA. Acesso em 11 fev. 2021.

Hardt, R. 2011. Da carstificação em arenitos. Aproximação com o suporte de geotecnologias. Rio Claro, 224 p. Tese (doutorado), Universidade Estadual Paulista Instituto de Geociências e Ciências Exatas.

ICMBIO. Instituto Chico Mendes de Conservação da Biodiversidade \& CECAV - Centro Nacional de Estudo, Proteção e Manejo de Cavernas. 2011. Apostila do III Curso de Espeleologia e Licenciamento Ambiental. Brasília/DF. 197p.

Ig. Transmissão e Distribuição. 2015. Relatório Ambiental Simplificado Linha de Transmissão LT 23KV Figueira/Ponta Grossa. In: Instituto Água e Terra - EIA-RIMA - editais. Disponível em: $\quad$ http://www.iat.pr.gov.br/Pagina/EIARIMA. Acesso em 11 fev. 2021.

Igplan. Consultoria Ambiental. 2010. Estudo Prévio de Impacto Ambiental PCH Castro. In: Instituto Água e Terra - EIA-RIMA - editais. Disponível em: http://www.iat.pr.gov.br/ Pagina/EIA-RIMA. Acesso em 11 fev. 2021.

Jansen, D.C., Cavalcanti, L.F. \& Lamblém, H.S. 2012. Mapa de potencialidade de ocorrência de cavernas no Brasil, na Escala 1:2.500.000. Revista Brasileira de Espeleologia, Brasília: CECAV, 2(1): 42-57.

Karmann, I. \& Sánchez, L.E. 1979. Distribuição das rochas carbonáticas e províncias espeleológicas do Brasil. Espeleotema, Monte Sião, 13: 105-167.

Karmann, I. \& Sánchez, L.E. 1986. Speleological provinces in Brazil. In: INTERNATIONAL
CONGRESS OF SPELEOLOGY, 9, 1986. Barcelona. Anais... Porto Alegre, UIS, v. 1, s/p. LACTEC. Instituto de Tecnologia para o Desenvolvimento. 2014. Estudo de Impactos Ambientais Complexo Eólico-Elétrico Campos Gerais. In: Instituto Água e Terra - EIA-RIMA editais. Disponível em: http://www.iat.pr.gov. br/Pagina/EIA-RIMA. Acesso em 11 fev. 2021. Maack, R. 1956. Fenômenos carstiformes de natureza climática e estrutural de arenitos do Estado do Paraná. Arquivos de Biologia e Tecnologia, 11:151-162.

Martins, S.B.M.P. 1985. Levantamento dos recursos naturais do distrito espeleológico de Altinópolis-SP. Rio Claro-SP. (Relatório FAPESP, proc. 83/2552-3).

Massuqueto, L.L. \& Pontes, H.S. 2017. Novos registros espeleológicos na APA da Escarpa Devoniana, Município de Ponta Grossa, Paraná. In. Pontes, H.S., Massuqueto, L.L., Mochiutti, N.F.B., Guimarães, G.B. (orgs.). SIMPÓSIO BRASILEIRO DE PATRIMÔNIO GEOLÓGICO, 4. 2017. Ponta Grossa. Anais... Ponta Grossa: p. 699-703.

Melo, M.S. \& Giannini, P.C.F. 2007. Sandstone dissolution landforms in the Furnas Formation, Southern Brazil. Earth Surface Processes and Landforms, 32: 2149-2164.

Melo, M.S., Guimarães, G.B., Chinelatto, A.L., Giannini, P.C.F., Pontes, H.S., Chinelatto, A.S.A. \& Atencio, D. 2015. Kaolinite, illite and quartz dissolution in the karstification of Paleozoic sandstones of the Furnas Formation, Parana Basin, Southern Brazil. Journal of South American Earth Sciences, 63: 20-35.

MMA. Ministério de meio Ambiente. 2017. Instrução Normativa MMA No 2, de 31 de agosto de 2017. Disponível em: http:// pesquisa.in.gov.br/imprensa/jsp/visualiza/ index.jsp?data=01/09/2017\&jornal=1\&pagina $=161$ \&totalArquivos=208. Acesso em $11 \mathrm{fev}$. 2021.

Mochiutti, N.F.B. \& Tomazzoli, E.R. 2017. Espeleotemas de uma caverna granítica na Ilha de Santa Catarina: uma análise preliminar. In: Rasteiro, M.A., Teixeira-Silva, C.M., Lacerda, S.G. (orgs.). CONGRESSO BRASILEIRO DE ESPELEOLOGIA, 34, 2017. Ouro Preto. Anais... Campinas: SBE, p. 327-333. 
Moura, V. 2011. Prospecção espeleológica, topografia e espeleometria de cavernas. In: III Curso de Espeleologia e licenciamento Ambiental. Instituto Chico Mendes de Conservação da Biodiversidade (ICMBio) \& Centro Nacional de Pesquisa e Conservação de Cavernas (CECAV). p. 45-71. Disponível em: http://www.icmbio.gov.br/cecav/images/ download/Apostila\%20Curso\%20de $\% 20$ Espeleologia\%20e\%20Licenciamento\%20 Ambiental.pdf. Acesso em 11 fev. 2021.

Parellada, C.I. 2017. Províncias Espeleológicas Paranaenses: uma revisão. In: Rasteiro, M.A. \& Santos-Neto, C.J.. (orgs.) CONGRESSO NACIONAL DE ESPELEOLOGIA, 20, 1989. Brasília. Anais... Campinas: SBE, p. 9-16.

Piló, L.B. \& Auler, A. S. 2009. Geoespeleologia das cavernas em rochas ferríferas da região de Carajás, PA. In: CONGRESSO BRASILEIRO DE ESPELEOLOGIA, 30, Montes Claros. Anais... Montes Claros: SBE, p.181-186.

Piló, L.B. \& Auler, A.S. 2011. Introdução à Espeleologia. In: III Curso de Espeleologia e licenciamento Ambiental. Instituto Chico Mendes de Conservação da Biodiversidade (ICMBio) \& Centro Nacional de Pesquisa e Conservação de Cavernas (CECAV). p. 7-23. Disponível em: http://www.icmbio.gov. br/cecav/images/download/Apostila\%20 Curso $\% 20$ de $\% 20$ Espeleologia $\% 20$ e $\% 20$ Licenciamento\%20Ambiental.pdf. Acesso em 11 fev. 2021.

PMPG. Prefeitura Municipal de Ponta Grossa. 2004. Lei no 7.636, de quatro de junho de 2004. Disponível em: https://leismunicipais. com.br/prefeitura/pr/pontagrossa?o=\&types= 28\&q=7.636. Acesso em 11 fev. 2021.

PMPG. Prefeitura Municipal de Ponta Grossa. 2005. Decreto $n^{0}$ 568, de dezessete de novembro de 2005. Disponível em: https:// leismunicipais.com.br/prefeitura/pr/ pontagrossa?o $=\& q=568 \% 2 F 2005$. Acesso em 11 fev. 2021.

PMPG. Prefeitura Municipal de Ponta Grossa. 2006. Lei n 8.473, de dois de março de 2006. Disponível em: https://leismunicipais.com. $\mathrm{br} /$ prefeitura/pr/pontagrossa?o= $\& \mathrm{q}=8.473$. Acesso em 11 fev. 2021.

PMPG. Prefeitura Municipal de Ponta Grossa.
2010. Lei no 10.417, de 17 de novembro de 2010. Disponível em: https://leismunicipais. com.br/prefeitura/pr/pontagrossa?o=\&types= 28\&q=10.417. Acesso em 11 fev. 2021.

PMPG. Prefeitura Municipal de Ponta Grossa. 2012. Lei no 11.233, de 27 de dezembro de 2012. Disponível em: https://leismunicipais. com.br/prefeitura/pr/pontagrossa?o=\&type $s=28 \& q=11.233 \% 2 F 2012$. Acesso em $11 \mathrm{fev}$. 2021.

PMPG. Prefeitura Municipal de Ponta Grossa. 2013. Decreto n 8.060, de 03 de dezembro de 2013. Disponível em: https:// leismunicipais.com.br/prefeitura/pr/ pontagrossa?o $\& q=8060 \% 2 F 2013$. Acesso em 11 fev. 2021.

PMPG. Prefeitura Municipal de Ponta Grossa. 2015a. Lei no 12.128, de 27 de dezembro de 2015. Disponível em: https://leismunicipais. com.br/prefeitura/pr/pontagrossa?o=\&types= 28\&q=+12.128. Acesso em 11 fev. 2021.

PMPG. Prefeitura Municipal de Ponta Grossa. 2015b. Lei no 12.192, de 25 de junho de 2015. Disponível em: https://leismunicipais.com. $\mathrm{br} /$ prefeitura $/ \mathrm{pr} /$ pontagrossa? $=$ \&types $=28$ $\& q=12.192$. Acesso em 11 fev. 2021.

PMPG. Prefeitura Municipal de Ponta Grossa. 2015c. Lei no 12.342, de 15 de dezembro de 2015. Disponível em: https://leismunicipais. com.br/prefeitura/pr/pontagrossa?o=\&types= 28\&q=12.342. Acesso em 11 fev. 2021.

PMPG. Prefeitura Municipal de Ponta Grossa. 2015d. Lei no 12.345, de 20 de novembro de 2015. Disponível em: https://leismunicipais. com.br/prefeitura/pr/pontagrossa?o=\&type $s=28 \& q=12345 \% 2 F 2015$. Acesso em 11 fev. 2021

PMPG. Prefeitura Municipal de Ponta Grossa. 2016. Decreto no 10.996, de 01 de fevereiro de 2016. Disponível em: https://leismunicipais. com.br/prefeitura/pr/pontagrossa?o=\&types= $5 \& q=10.996$. Acesso em 11 fev. 2021.

PMPG. Prefeitura Municipal de Ponta Grossa. 2018a. Decreto no 13.957, de 17 de janeiro de 2018. Disponível em: https://leismunicipais. com.br/prefeitura/pr/pontagrossa?o=\&types= 5\&q=13.957. Acesso em 11 fev. 2021.

PMPG. Prefeitura Municipal de Ponta Grossa. 2018b. Decreto nº 14.085, de 20 de fevereiro de 
2018. Disponível em: https://leismunicipais. com.br/prefeitura/pr/pontagrossa?o=\&types= $5 \& q=14.085$. Acesso em 11 fev. 2021.

Pontes, H.S. 2019. Patrimônio geológico cárstico em e políticas públicas de geoconservação, com base em estudo de caso do município de Ponta Grossa (PR). Curitiba. 226 p.Tese de Doutorado - Universidade Federal do Paraná, Setor de Ciências da Terra, Programa de Pósgraduação em Geologia.

Pontes, H.S. \& Massuqueto, L.L. 2016. Riscos eminentes ao patrimônio cárstico não carbonático dos Campos Gerais do Paraná: conflitos na conceituação, lacunas na legislação ou negligência? In: XI SINAGEO SIMPÓSIO NACIONAL DE GEOMORFOLOGIA. Maringá. Anais... Maringá, UGB - União da Geomorfologia Brasileira, sem páginas. Disponível em: http://www.sinageo.org. br/2016/trabalhos/9/9-499-133.html. Acesso em 11 fev. 2021.

Pontes, H.S., Massuqueto, L.L., Fernandes, L.A., Foltran, A.C., Melo, M.S. \& Moreira J.C., 2018b. Caves geodiversity evaluation as an instrument to the management of the Campos Gerais National Park, Southern Brazil. Geoheritage, 10(1): 1-11.

Pontes, H.S., Massuqueto, L.L., Foltran, A.C., Pontes, F.S., Guimarães, G.B., Mochiutti, N.F.B., Guimarães, S.K., Burgardt, S., do Vale, T.F. \& Feitosa, N.M.N. 2018a. Patrimônio espeleológico do Parque Nacional dos Campos Gerais: Ações prioritárias para o manejo e propostas de ampliações da Unidade de Conservação. Grupo Universitário de Pesquisas Espeleológicas - GUPE - Ponta Grossa. Disponível em: https://issuu.com/ gupe.espeleo/docs/patrim_nio_espeleol_ gico_do_parque_. Acesso em 11 fev. 2021.

Pontes, H.S., Massuqueto, L.L., Guimarães, G. B., Mochiutti, N.F.B, Silva, A.G.C., Foltran, A.C., Vale, T.F. 2019 - Sistema de cavernas Fenda Sem Fim, Parque Nacional dos Campos Gerais, Ponta Grossa, Paraná. In: CONGRESSO BRASILEIRO DE ESPELEOLOGIA, 35. Bonito. Anais... Campinas: SBE. Sem páginas.

Resitec. Consultoria Ambiental. 2007. Estudo de Impactos Ambientais Central de Tratamento de Resíduos Furnas (CTR/Furnas). Documento interno de acesso restrito. (sem páginas).

Recitech. Consultoria Ambiental. 2016. Relatório Ambiental Simplificado CGH São João. In: Instituto Água e Terra - EIA-RIMA - editais. Disponível em: http://www.iat.pr.gov.br/ Pagina/EIA-RIMA. Acesso em 11 fev. 2021.

Rodet, J. 2014. The primokarst, former stages of karstification, or how solution caves are born. Geologica Belgica. 17(1): 58-65.

Sauro, F. 2014. Speleogenesis and secondary cave minerals in quartz-sandstone and quartzite environment. Bologna. 254p. Tese de Doutorado. Alma Mater Studiorum Università di Bologna.

Silva, M.D. 2018. Gênese e evolução das cavernas marinhas do maciço costeiro do Pântano do Sul, Ilha de Santa Catarina (SC). Florianópolis. 238p. Tese de doutorado, Universidade Federal de Santa Catarina.

SMMA. Secretaria Municipal de Meio Ambiente. 2017a. Instrução Normativa SMMA $n^{\circ}$ 1-001/2017. Disponível em: https:// smma.pontagrossa.pr.gov.br/download/ licenciamento/1-extracao-mineral/1.1cascalheira/1.001-geral/IN_LA_1-001_2017SMMA.pdf. Acesso em 11 fev. 2021.

SMMA. Secretaria Municipal de Meio Ambiente. 2017b. Instrução Normativa SMMA $n^{\circ}$ 1-002/2017. Disponível em: https:// smma.pontagrossa.pr.gov.br/download/ licenciamento/1-extracao-mineral/1.2extracao-de-pedras-irregulares-de-modoartesanal/1.002-geral/IN_LA_1-002_2017SMMA.pdf. Acesso em 11 fev. 2021.

SMMA. Secretaria Municipal de Meio Ambiente. 2017c. Instrução Normativa SMMA $n^{\circ}$ 2-001/2017. Disponível em: https:// smma.pontagrossa.pr.gov.br/download/ licenciamento/2-atividades-agropecuariase-silviculturais/2.1-suinocultura/IN_LA_2001_2017-SMMA.pdf. Acesso em 11 fev. 2021.

SMMA. Secretaria Municipal de Meio Ambiente. 2017d. Instrução Normativa SMMA n 10-001/2017. Disponível em: https:// smma.pontagrossa.pr.gov.br/download/ licenciamento/10-empreendimentosimobiliarios/10.1-loteamentos/IN_LA_10001_2017-SMMA.pdf. Acesso em 11 fev. 
2021.

SMMA. Secretaria Municipal de Meio Ambiente. 2017e. Instrução Normativa SMMA $n^{\circ}$ 10-002A/2017. Disponível em: https:// smma.pontagrossa.pr.gov.br/download/ licenciamento/10-empreendimentosimobiliarios/10.2-implantacao-de-conjuntoshabitacionais/10.2A-conjunto-habitacionalgeral/IN_LA_10-002A_2018-SMMA.pdf. Acesso em 11 fev. 2021.

SMMA. Secretaria Municipal de Meio Ambiente. 2021. ATAS do CONDEMA. Disponível em: https://smma.pontagrossa.pr.gov.br/ conselhos/. Acesso em 11 fev. 2021.

Soma. Consultoria Ambiental. 2011. Estudo de Impactos Ambientais UHE Telêmaco Borba. In: Instituto Água e Terra - EIA-RIMA editais. Disponível em: http://www.iat.pr.gov. br/Pagina/EIA-RIMA. Acesso em 11 fev. 2021.

Soma. Consultoria Ambiental. 2013. Estudo de Impactos Ambientais UHE Tibagi Montante. In: Instituto Água e Terra - ElA-RIMA editais. Disponível em: http://www.iat.pr.gov. br/Pagina/EIA-RIMA. Acesso em 11 fev. 2021.

Spoladore, A.. 2005. Novas cavernas em arenito no Estado do Paraná. In: Congresso Brasileiro de Espeleologia, 28. Campinas. Anais... Campinas. p. 125-135.

Titanium. Consultoria Ambiental. 2015. Estudo de Impactos Ambientais UHE Santa Branca. In: Instituto Água e Terra - ElA-RIMA editais. Disponível em: http://www.iat.pr.gov. br/Pagina/EIA-RIMA. Acesso em 11 fev. 2021.

Wray, R.A.L., SAURO, F. 2017. An updated global review of solutional weathering processes and forms in quartz sandstones and quartzites. Earth-Science Reviews, 171: 520-557. 